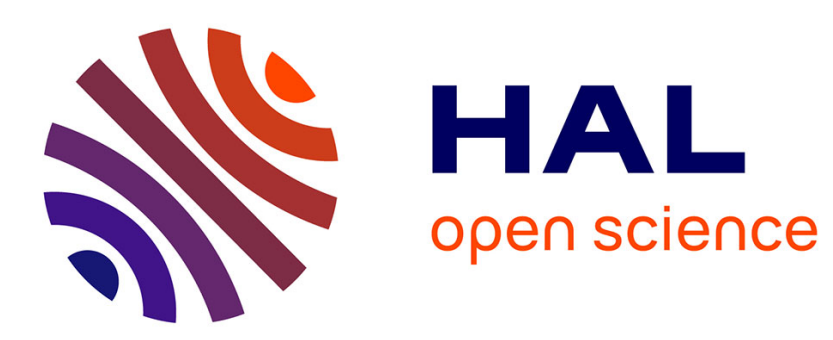

\title{
Behaviour of apricot (Prunus armeniaca L.) cultivars in the presence of sharka (plum pox potyvirus): a review
}

P. Martínez-Gómez, F. Dicenta, J. Audergon

\section{To cite this version:}

P. Martínez-Gómez, F. Dicenta, J. Audergon. Behaviour of apricot (Prunus armeniaca L.) cultivars in the presence of sharka (plum pox potyvirus): a review. Agronomie, 2000, 20 (4), pp.407-422. 10.1051/agro:2000137 . hal-00886049

\section{HAL Id: hal-00886049 https://hal.science/hal-00886049}

Submitted on 1 Jan 2000

HAL is a multi-disciplinary open access archive for the deposit and dissemination of scientific research documents, whether they are published or not. The documents may come from teaching and research institutions in France or abroad, or from public or private research centers.
L'archive ouverte pluridisciplinaire HAL, est destinée au dépôt et à la diffusion de documents scientifiques de niveau recherche, publiés ou non, émanant des établissements d'enseignement et de recherche français ou étrangers, des laboratoires publics ou privés. 


\title{
Behaviour of apricot (Prunus armeniaca L.) cultivars in the presence of sharka (plum pox potyvirus): a review
}

\author{
P. MArtínez-GómeZ ${ }^{\mathrm{a}}$, F. Dicenta ${ }^{\mathrm{a} *}$, J.M. AUdERGON $^{\mathrm{b}}$ \\ a Departamento de Mejora y Patología Vegetal, CEBAS-CSIC, Apartado 4195, E-30080 Murcia, Spain \\ ${ }^{\mathrm{b}}$ Unité de Génétique et Amélioration des Fruits et Légumes, INRA, Site Agroparc, \\ Domaine Saint Paul, F-84914 Avignon, Cedex 9, France
}

(Received 21 October 1999; accepted 7 March 2000)

\begin{abstract}
Information concerning the evaluation of apricot resistance to sharka (plum pox potyvirus) has in many cases been published in journals of limited circulation. In an attempt to assess the actual status of this resistance, a global review has been made, including 222 cultivars, 175 of which can be considered as susceptible, 27 as resistant and 20 as cultivars of uncertain classification. Such a doubtful classification could be due to differences in evaluation methods, the isolates used, or to the authenticity of the plant material. The results seem to indicate that the main origin of resistance to sharka could be North American cultivars, although other resistant sources have been found in Central Europe.
\end{abstract}

Prunus armeniaca L. / apricot / plum pox potyvirus / sharka / resistance

Résumé - Comportement des cultivars d'abricotier (Prunus armenica L.) à la sharka (plum pox potyvirus) : une revue. Les informations concernant l'évaluation du comportement de l'abricotier à la sharka sont fréquemment publiées dans des journaux à faible audience. La présente revue se propose de synthétiser ces informations dispersées : 222 cultivars sont pris en compte, 175 d'entre eux pouvant être considérés comme sensibles, 27 comme résistants et 20 pour lesquels la classification est incertaine. Cette classification douteuse peut être due à des différences dans les méthodes d'évaluation, aux isolats utilisés ou à l'authenticité du matériel végétal. Les résultats semblent indiquer que la principale source de résistance à la sharka aurait pour origine les cultivars nord-américains bien que d'autres sources de résistance ont été trouvées en Europe centrale.

Prunus armenica L. / abricotier / plum pox potyvirus / sharka / résistance

Communicated by Hervé Thiellement (Geneva, Switzerland)

* Correspondence and reprints

fdicenta@natura.cebas.csic.es 


\section{Introduction}

Sharka, a disease produced by plum pox potyvirus (PPV), is one of the most important limiting factors in apricot cultivation. Described for the first time in Bulgaria at about the time of the First World War [3], it spread throughout Europe [45], North Africa [21], India [50], Chile [2] and, more recently, the USA [9].

Sharka affects most species of the genus Prunus, especially apricot, peach and plum trees $[31,36]$. It also affects cherries $[11,25]$ and has been experimentally transmitted to almond [12].

PPV is characterised by its wide genetic variability, although two main isolates have been described in Europe: Dideron (D) and Marcus (M) [10]. Other less widespread isolates have also been described: El Amar (E) [52] and Cherry (SoC) [35].

The use of certified healthy plant material is one of the key elements for orchard protection [30, 37, 43]. In infected areas, the uprooting of diseased trees avoids uncontrolled spreading, but does not guarantee eradication [16] due to non-persistent aphid transmission and the time elapsing between inoculation and the appearance of symptoms. A long term solution must involve the cultivation of resistant cultivars $[4,15,22,28,31]$.

All cultivars of European origin have been demonstrated as sharka-susceptible in field trials $[26,27,49]$, while the first cultivars to be confirmed as resistant came from North America [26, 47]. However, the direct use of these cultivars in Europe has been ruled out since they are generally self-incompatible, produce low-quality fruits and have high chilling requirements. For this reason, European efforts have concentrated on obtaining new resistant cultivars $[4,22,29,38]$, and on providing an objective characterisation of the level of resistance of the cultivars in use.

The transmission of such resistance to the descendants of resistant cultivars such as 'Stark Early Orange' $[19,20]$ or 'Stella' $[6,14]$ has also been studied. This transmission of resistance in apricot has been described as an oligogenic characteristic in some cases $[18,19]$, and, more recently, as a monogenic characteristic [17].
The existent information regarding the susceptibility or resistance of an apricot cultivar to PPV is not easily compiled, since it may be contained in a variety of publications, many of which have a limited readership. Furthermore, the characterisation of cultivar susceptibility is occasionally contradictory because of differences in evaluation conditions, sites, strains and possible discrepancies in the plant material.

The purpose of this study was to provide a synthesis of the information available on the resistance or susceptibility of apricot cultivars to PPV, based on a review of the bibliography, which refers to the evaluation of cultivars in different conditions and using different isolates.

\section{Methodology}

In order to compare the different information, the following criteria were recorded: i) cultivar: native name of the apricot cultivar studied; ii) origin: country of origin of the cultivar; iii) level of resistance: the classification of cultivar resistance depends on the authors cited as reference [4, 24, 31]. The scheme proposed in this review is classified into three different levels: s: susceptible, cultivars showing symptoms after infection; t: tolerant, cultivars without symptoms after infection, which react positively to the serological ELISA test (+); r: resistant cultivars without symptoms after infection and which test negative to the serological ELISA test (-).

\subsection{Evaluation conditions}

The evaluation conditions were as follows: $\mathrm{f}$ : in the field, in the open air; gh: in the controlled conditions of an insect-proof greenhouse.

\subsection{Inoculation}

The type of inoculation was as follows: n: natural inoculation (by aphids); c: chip or chip-budding 
inoculation (grafting) with a controlled infected source; $\mathrm{x}$ : grafting onto a heavily infected adult tree.

\subsection{Isolate}

The isolates used in a controlled inoculation or strain type present in the area in natural infection conditions were as follows: M: Marcus; D: Dideron; E: El Amar.

\subsection{Years}

This parameter concerned the number of years studied in the field or the number of vegetative cycles studied in controlled greenhouse or screenhouse conditions.

\subsection{Leaf symptoms}

Most authors use a scale of between 0 (no symptoms) and 3 (maximum expression of symptoms), although some studies refer to a scale of $0-5$. We used a scale of $0-3$ and converted the data of the latter system to this scale. In some cases, the evaluation was only reported in term of presence $(+)$ or absence (-) of symptoms.

\subsection{Fruit symptoms}

A similar scale (0-3) to that reported above was used. This scale was used in all the references studied: $0=$ absence of symptoms; $1=$ slight yellowish ring symptoms; $2=$ clear yellow symptoms; $3=$ strong symptoms with fruit deformation.

\subsection{Detection techniques}

The application of different techniques has been mentioned, for example enzyme like immunosorbent assay (ELISA), immuno capture reverse transciptase polymerase chain reaction (IC-RT-PCR), immunosorbent electron microscopy (ISEM) or tissue printing (TP). The type of reaction is described as positive $(+)$ or negative $(-)$.

\subsection{References}

The references used were those found in the literature. The information obtained was organised into three different tables as a function of the degree of susceptibility attributed to the different cultivars by each author.

\section{Results and discussion}

This survey of apricot cultivar susceptibility indicated the existence of 3 categories: susceptible, resistant, and cultivars that were classified differently by different authors. According to this classification, most cultivars (175) were considered to be susceptible (Tab. I); only 27 were described as completely resistant (Tab. II); and 20 were of uncertain classification (Tab. III).

Most of the registered data was from 3 different origins:

- Natural infection in the field, with $\mathrm{M}$ strains in Central European countries and Greece [8, 27, 47, $48,51]$, D strains in Spain [7, 44] and $M$ and D strains in France [6, 18].

- Controlled infection in the field in Yugoslavia [42], the Czech Republic [38-40, 46] and in Greece [29] with M strains.

- Controlled infection in insect-proof greenhouse or screen-house with $M$ and $D$ strains in France [4, 5, 18-20], and D strains in Germany [24] and in Spain [32-34].

As regards the number of years the studies lasted, those carried out in the field in natural infection conditions or by grafting onto diseased trees lasted between one and ten years, while the assays carried out in sealed greenhouses and involving artificial inoculation were considerably shorter, lasting one or two years only (two or four growth cycles). It seems that the evaluation of resistance in controlled conditions (controlled inoculation) is a more rapid undertaking than in conditions of natural infection (by aphids), although the former, it must be admitted, is also more laborious. Grafting onto infected trees in the field is the more effective and easier evaluation method. 
Table I. Apricot cultivars generally described as susceptible to plum pox potyvirus.

\begin{tabular}{|c|c|c|c|c|c|c|c|c|c|}
\hline Cultivar & Origin & Eval & Inoc & Isol & Year & Le $\mathrm{s}$ & Fr s & $\mathrm{D} \mathrm{t}$ & Reference \\
\hline Amabile Vecchioni & Italy & gh & $\mathrm{C}$ & M & 3 & $+(1)$ & & $+(2)$ & Dosba et al, 1992 \\
\hline Amal & Tunisia & $\mathrm{f}$ & $\mathrm{N}$ & M & 4 & 2.4 & 2.8 & & Karayiannis, 1989 \\
\hline Ambrosia & Germany & $\mathrm{f}$ & $\mathrm{N}$ & M & 1 & 3.0 & 2.0 & & Audergon et al. $1995 \mathrm{~b}$ \\
\hline Aprikoz & Turkey & $\mathrm{f}$ & $\mathrm{N}$ & M & 4 & 3.0 & 2.2 & & Elibüyük and Erdiller, 1995 \\
\hline Arrogantes & Spain & $\mathrm{f}$ & $\mathrm{N}$ & $\mathrm{D}$ & 2 & 0.5 & & & Rodríguez et al, 1995 \\
\hline Avikour & France & gh & $\mathrm{C}$ & M & 3 & $+(1)$ & & $+(2)$ & Dosba et al, 1992 \\
\hline \multirow[t]{2}{*}{ Avignel } & France & $\mathrm{f}$ & $\mathrm{N}$ & M & 1 & $+(1)$ & & & Audergon et al., 1995b \\
\hline & & gh & $\mathrm{C}$ & M & 3 & $+(1)$ & & $+(2)$ & Dosba et al, 1992 \\
\hline Bademovidna & Yugoslavia & $\mathrm{f}$ & $\mathrm{N}$ & M & 1 & 1.0 & 3.0 & & Audergon et al, 1995b \\
\hline Balady & Syria & $\mathrm{f}$ & $\mathrm{N}$ & $\mathrm{E}$ & 3 & $+{ }^{(1)}$ & & & Aboul-Ela et al, 1999 \\
\hline Banaesa & Yugoslavia & gh & $\mathrm{C}$ & M & 3 & $+(1)$ & & $+(2)$ & Dosba et al, 1992 \\
\hline Baracca & Italy & $\mathrm{f}$ & $\mathrm{N}$ & M & 4 & 2.3 & 2.8 & & Karayiannis, 1989 \\
\hline \multirow[t]{7}{*}{ Bebecou } & Greece & $\mathrm{gh}$ & $\mathrm{C}$ & M & 3 & $+(1)$ & & $+(2)$ & Dosba et al, 1988 \\
\hline & & gh & $\mathrm{C}$ & $\mathrm{D}$ & 2 & 2.5 & & & Audergon et al, 1994 \\
\hline & & $\mathrm{gh}$ & $\mathrm{c}$ & $\mathrm{D}$ & 2 & 2.5 & & & Audergon et al, 1995a \\
\hline & & gh & $\mathrm{c}$ & $\mathrm{D}$ & 1 & $+(1)$ & & $+(5)$ & Dicenta and Audergon, 1995 \\
\hline & & $\mathrm{f}$ & $\mathrm{n}$ & M & 4 & 2.3 & 2.5 & & Karayiannis, 1989 \\
\hline & & $\mathrm{f}$ & $\mathrm{n}$ & M & 1 & 3.0 & 2.0 & & Audergon et al, 1995b \\
\hline & & $\mathrm{f}$ & $\mathrm{n}$ & M & 5 & 2.3 & 2.5 & & Audergon et al, 1995a \\
\hline \multirow[t]{3}{*}{ Bergeron } & France & $\mathrm{f}$ & $\mathrm{n}$ & M & 4 & 2.3 & 2.5 & & Karayiannis, 1989 \\
\hline & & gh & $\mathrm{c}$ & M & 3 & $+{ }^{(1)}$ & & $+(2)$ & Dosba et al, 1988 \\
\hline & & $\mathrm{f}$ & $\mathrm{c}$ & M & 5 & 3.0 & & & Sedlakova and Gallo, 1994 \\
\hline Best of Hungary & Romania & $\mathrm{f}$ & $\mathrm{n}$ & M & 4 & 3.0 & 3.0 & & Balan and Stoian, 1995 \\
\hline Blanco de Ceutí & Spain & $\mathrm{f}$ & $\mathrm{n}$ & M & 1 & 3.0 & 2.0 & & Audergon et al, 1995b \\
\hline Blenheim & USA & $\mathrm{f}$ & $\mathrm{n}$ & M & 4 & 2.2 & 2.8 & & Karayiannis, 1989 \\
\hline Blentyl & USA & $\mathrm{f}$ & $\mathrm{n}$ & M & 4 & 1.0 & 3.0 & & Balan and Stoian, 1995 \\
\hline \multirow[t]{2}{*}{ Boccucia } & Italy & $\mathrm{f}$ & $\mathrm{n}$ & M & 4 & 2.4 & 2.8 & & Karayiannis, 1989 \\
\hline & & $\mathrm{f}$ & $\mathrm{n}$ & M & 4 & 3.0 & 3.0 & & Balan and Stoian, 1995 \\
\hline Breda & Germany & $\mathrm{f}$ & $\mathrm{n}$ & M & 4 & 2.0 & 0.0 & & Karayiannis, 1989 \\
\hline \multirow[t]{3}{*}{ Búlida } & Spain & gh & $\mathrm{c}$ & $\mathrm{D}$ & 2 & 0.6 & & $+(2)$ & Martínez-Gómez and Dicenta, 2000 \\
\hline & & $\mathrm{f}$ & $\mathrm{n}$ & M & 4 & 2.3 & 2.8 & & Karayiannis, 1989 \\
\hline & & $\mathrm{f}$ & $\mathrm{n}$ & M & 1 & 3.0 & 1.0 & & Audergon et al, 1995b \\
\hline Cafona & Italy & $\mathrm{f}$ & $\mathrm{n}$ & M & 4 & 3.0 & 3.0 & & Balan and Stoian, 1995 \\
\hline Caldesi & Italy & $\mathrm{f}$ & $\mathrm{n}$ & M & 1 & $+(1)$ & & & Audergon et al, 1995b \\
\hline Canette & Italy & $\mathrm{f}$ & $\mathrm{n}$ & M & 4 & 3.0 & 3.0 & & Balan and Stoian, 1995 \\
\hline \multirow[t]{8}{*}{ Canino } & Spain & $\mathrm{f}$ & $\mathrm{c}$ & $\mathrm{D}$ & 1 & 3.0 & 1.0 & & Avinent et al, 1993 \\
\hline & & $\mathrm{f}$ & $\mathrm{n}$ & $\mathrm{D}$ & 2 & 2.3 & 1.8 & & Rodríguez et al, 1995 \\
\hline & & $\mathrm{gh}$ & $\mathrm{c}$ & $\mathrm{D}$ & 2 & 1.4 & & $-(2)$ & Martínez-Gómez and Dicenta, 2000 \\
\hline & & $\mathrm{gh}$ & $\mathrm{c}$ & M & 3 & $+(1)$ & & $+(2)$ & Dosba et al, 1988 \\
\hline & & $\mathrm{f}$ & $\mathrm{n}$ & M & 4 & 2.5 & 3.0 & & Karayiannis, 1989 \\
\hline & & gh & $\mathrm{c}$ & M & 3 & $+(1)$ & & $+(2)$ & Dosba et al, 1991 \\
\hline & & $\mathrm{f}$ & $\mathrm{n}$ & M & 1 & 3.0 & 3.0 & & Audergon et al, 1995b \\
\hline & & $\mathrm{f}$ & $\mathrm{n}$ & M & 4 & 3.0 & 3.0 & & Balan and Stoian, 1995 \\
\hline Cañahueca & Spain & $\mathrm{f}$ & $\mathrm{n}$ & $\mathrm{D}$ & 2 & 1.0 & 2.1 & & Rodríguez et al, 1995 \\
\hline Carrascal & Spain & $\mathrm{gh}$ & $\mathrm{c}$ & M & 3 & $+(1)$ & & $+(2)$ & Dosba et al, 1992 \\
\hline Carrichosa & Spain & $\mathrm{f}$ & $\mathrm{n}$ & $\mathrm{D}$ & 2 & 0.1 & 0.1 & & Rodríguez et al, 1995 \\
\hline \multirow[t]{2}{*}{ Castlebrite } & $?$ & $\mathrm{gh}$ & $\mathrm{c}$ & M & 3 & $+(1)$ & & $+(2)$ & Dosba et al, 1992 \\
\hline & & $\mathrm{f}$ & $\mathrm{n}$ & M & 1 & $+(1)$ & & & Audergon et al, 1995b \\
\hline Cegledi & $?$ & gh & $\mathrm{c}$ & M & 3 & $+(1)$ & & $+(2)$ & Dosba et al, 1992 \\
\hline
\end{tabular}


Table I. (continued).

\begin{tabular}{|c|c|c|c|c|c|c|c|c|c|}
\hline Cultivar & Origin & Eval & Inoc & Isol & Year & Le $\mathrm{s}$ & Fr s & $\mathrm{D} \mathrm{t}$ & Reference \\
\hline \multirow[t]{3}{*}{ Cöloglu } & Turkey & gh & $\mathrm{c}$ & M & 3 & $+(1)$ & & $+(2)$ & Dosba et al, 1992 \\
\hline & & $\mathrm{f}$ & $\mathrm{n}$ & M & 1 & $+(1)$ & & & Audergon et al, 1995b \\
\hline & & $\mathrm{f}$ & $\mathrm{n}$ & M & 4 & 3.0 & 2.2 & & Elibüyük and Erdiller, 1995 \\
\hline \multirow[t]{5}{*}{ Colomer } & France & gh & $\mathrm{c}$ & $\mathrm{D}$ & 2 & 2.8 & & & Audergon et al, 1994 \\
\hline & & gh & $\mathrm{c}$ & $\mathrm{D}$ & 2 & 3 & & & Audergon et al, 1995a \\
\hline & & gh & $\mathrm{c}$ & $\mathrm{D}$ & 1 & $+(1)$ & & $+(5)$ & Dicenta and Audergon, 1995 \\
\hline & & gh & $\mathrm{c}$ & M & 3 & $+(1)$ & & $+(2)$ & Dosba et al, 1988 \\
\hline & & $\mathrm{f}$ & $\mathrm{n}$ & M & 1 & 2.2 & 3.0 & & Audergon et al, 1995a \\
\hline Colorao & Spain & $\mathrm{f}$ & $\mathrm{n}$ & $\mathrm{D}$ & 2 & 1.6 & 1.4 & & Rodríguez et al, 1995 \\
\hline Colorao Antón & Spain & $\mathrm{f}$ & $\mathrm{n}$ & $\mathrm{D}$ & 2 & 1.9 & 2.1 & & Rodríguez et al, 1995 \\
\hline \multirow[t]{2}{*}{ Comandor } & Romania & $\mathrm{f}$ & $\mathrm{n}$ & M & 4 & 1.0 & 1.2 & & Balan and Stoian, 1995 \\
\hline & & $\mathrm{gh}$ & $\mathrm{c}$ & M & 3 & $+(1)$ & & $+(2)$ & Dosba et al, 1992 \\
\hline Competna & $?$ & $\mathrm{f}$ & $\mathrm{n}$ & M & 1 & 3.0 & 1.0 & & Audergon et al, 1995b \\
\hline \multirow[t]{2}{*}{ Corbató } & Spain & $\mathrm{f}$ & $\mathrm{c}$ & $\mathrm{D}$ & 1 & 3.0 & 1.0 & & Avinent et al, 1993 \\
\hline & & $\mathrm{f}$ & $\mathrm{n}$ & M & 1 & 3.0 & 2.0 & & Audergon et al, 1995b \\
\hline Cortos Archena & Spain & $\mathrm{f}$ & $\mathrm{n}$ & $\mathrm{D}$ & 2 & 0.1 & & & Rodríguez et al, 1995 \\
\hline \multirow[t]{4}{*}{ Currot } & Spain & $\mathrm{f}$ & $\mathrm{c}$ & $\mathrm{D}$ & 1 & 3.0 & 3.0 & & Avinent et al, 1993 \\
\hline & & $\mathrm{f}$ & $\mathrm{n}$ & $\mathrm{D}$ & 2 & 2.4 & 2.9 & & Rodríguez et al, 1995 \\
\hline & & gh & $\mathrm{c}$ & $\mathrm{D}$ & 2 & 1.0 & & $+(2)$ & Martínez-Gómez and Dicenta, 2000 \\
\hline & & $\mathrm{f}$ & $\mathrm{n}$ & M & 1 & 3.0 & 3.0 & & Audergon et al, 1995b \\
\hline Chirivello & Italy & $\mathrm{f}$ & $\mathrm{n}$ & M & 1 & 3.0 & 3.0 & & Audergon et al, $1995 \mathrm{~b}$ \\
\hline Da Ju Bada & China & $\mathrm{f}$ & $\mathrm{x}$ & M & 1 & 2.0 & & $+^{(2)(3)}$ & Polák et al, $1995 \mathrm{~b}$ \\
\hline \multirow[t]{2}{*}{ Dacia } & Romania & $\mathrm{f}$ & $\mathrm{n}$ & M & 4 & 1.5 & 1.5 & & Balan and Stoian, 1995 \\
\hline & & $\mathrm{f}$ & $\mathrm{x}$ & M & 4 & 2.0 & 2.0 & $+^{(2)(4)}$ & Polák et al, 1997 \\
\hline Damasco & Spain & $\mathrm{f}$ & $\mathrm{n}$ & $\mathrm{D}$ & 2 & 0.2 & 1.7 & & Rodríguez et al, 1995 \\
\hline \multirow[t]{2}{*}{ De Olanda } & France & $\mathrm{f}$ & $\mathrm{n}$ & M & 4 & 3.0 & 1.0 & & Balan and Stoian, 1995 \\
\hline & & gh & $\mathrm{c}$ & M & 3 & $+(1)$ & & $+(2)$ & Dosba et al, 1992 \\
\hline Desfarges & $?$ & $\mathrm{f}$ & $\mathrm{n}$ & M & 1 & $+(1)$ & & & Audergon et al, 1995b \\
\hline Diamantopoulou & Greece & $\mathrm{f}$ & $\mathrm{n}$ & M & 4 & 2.7 & 3.0 & & Karayiannis, 1989 \\
\hline Dioses & Spain & $\mathrm{f}$ & $\mathrm{n}$ & $\mathrm{D}$ & 2 & 0.0 & 1.0 & & Rodríguez et al, 1995 \\
\hline Dobruganska & Yugoslavia & $\mathrm{f}$ & $\mathrm{n}$ & M & 4 & 2.2 & 3.0 & & Karayiannis, 1989 \\
\hline Don Gaetano & Italy & $\mathrm{f}$ & $\mathrm{n}$ & M & 4 & 3.0 & 3.0 & & Balan and Stoian, 1995 \\
\hline Dryanovska & $?$ & $\mathrm{f}$ & $\mathrm{n}$ & M & 4 & 2.3 & 2.8 & & Karayiannis, 1989 \\
\hline Early Bee & USA & $\mathrm{f}$ & $\mathrm{n}$ & M & 4 & 3.0 & 2.2 & & Balan and Stoian, 1995 \\
\hline Early Divinity & USA & $\mathrm{gh}$ & $\mathrm{c}$ & M & 3 & $+(1)$ & & $+(2)$ & Dosba et al, 1992 \\
\hline Early Golden & USA & $\mathrm{f}$ & $\mathrm{n}$ & M & 4 & 3.0 & 3.0 & & Balan and Stoian, 1995 \\
\hline \multirow[t]{3}{*}{ Erevani } & Italy & $\mathrm{f}$ & $\mathrm{n}$ & M & 4 & 2.7 & 1.3 & & Karayiannis, 1989 \\
\hline & & gh & $\mathrm{c}$ & M & 3 & $+(1)$ & & $+(2)$ & Dosba et al, 1992 \\
\hline & & $\mathrm{f}$ & $\mathrm{n}$ & M & 1 & 3.0 & 2.0 & & Audergon et al, 1995b \\
\hline Eugenios & Spain & $\mathrm{f}$ & $\mathrm{n}$ & $\mathrm{D}$ & 2 & 0.7 & 1.2 & & Rodríguez et al, 1995 \\
\hline \multirow[t]{2}{*}{ Favorit } & Romania & $\mathrm{f}$ & $\mathrm{n}$ & M & 1 & 3.0 & 1.0 & & Audergon et al, 1995b \\
\hline & & $\mathrm{f}$ & $\mathrm{n}$ & M & 4 & 3.0 & 1.8 & & Balan and Stoian, 1995 \\
\hline Fenómeno & Spain & $\mathrm{f}$ & $\mathrm{n}$ & $\mathrm{D}$ & 2 & $+(1)$ & 1.9 & & Rodríguez et al, 1995 \\
\hline Festivalna & Italy & $\mathrm{f}$ & $\mathrm{n}$ & M & 4 & 2.2 & 0.7 & & Karayiannis, 1989 \\
\hline Gergana & $?$ & $\mathrm{f}$ & $\mathrm{n}$ & $\mathrm{M}$ & 1 & 3.0 & 3.0 & & Audergon et al, 1995b \\
\hline \multirow[t]{2}{*}{ Ginesta } & Spain & $\mathrm{f}$ & $\mathrm{c}$ & $\mathrm{D}$ & 1 & 3.0 & 2.0 & & Avinent et al, 1993 \\
\hline & & $\mathrm{f}$ & $\mathrm{n}$ & M & 1 & 3.0 & 3.0 & & Audergon et al, 1995b \\
\hline Gitano & Spain & $\mathrm{f}$ & $\mathrm{n}$ & M & 1 & 3.0 & 2.0 & & Audergon et al, 1995b \\
\hline Grossa Giardino & Italy & $\mathrm{f}$ & $\mathrm{n}$ & M & 4 & 2.3 & 1.8 & & Karayiannis, 1989 \\
\hline
\end{tabular}


Table I. (continued).

\begin{tabular}{|c|c|c|c|c|c|c|c|c|c|}
\hline Cultivar & Origin & Eval & Inoc & Isol & Year & Le $\mathrm{s}$ & Fr s & $\mathrm{D} \mathrm{t}$ & Reference \\
\hline Helena Roussillon & France & gh & $\mathrm{c}$ & M & 3 & $+(1)$ & & $+(2)$ & Dosba et al, 1988 \\
\hline \multirow[t]{2}{*}{ Hacihaliloglu } & Turkey & $\mathrm{gh}$ & $\mathrm{c}$ & M & 3 & $+(1)$ & & $+(2)$ & Dosba et al, 1992 \\
\hline & & $\mathrm{f}$ & $\mathrm{n}$ & M & 4 & 3.0 & 2.2 & & Elibüyük and Erdiller, 1995 \\
\hline Hamawey & Egypt & $\mathrm{f}$ & $\mathrm{n}$ & $\mathrm{E}$ & 3 & $+(1)$ & & $+(2)$ & Aboul-Ela et al, 1999 \\
\hline \multirow{2}{*}{ Harogem } & Canada & $\mathrm{gh}$ & $\mathrm{c}$ & M & 3 & $+(1)$ & & $+(2)$ & Dosba et al., 1992 \\
\hline & & $\mathrm{f}$ & $\mathrm{n}$ & M & 4 & 2.1 & 3.0 & & Karayiannis, 1989 \\
\hline Harglow & Canada & $\mathrm{f}$ & $\mathrm{n}$ & M & 1 & $+(1)$ & & & Audergon et al, 1995b \\
\hline \multirow[t]{2}{*}{ Hargrand } & Canada & gh & $\mathrm{c}$ & M & 3 & $+(1)$ & & $+(2)$ & Dosba et al, 1992 \\
\hline & & $\mathrm{f}$ & $\mathrm{n}$ & M & 1 & $+(1)$ & & & Audergon et al, 1995b \\
\hline \multirow[t]{2}{*}{ Hasanbey } & $?$ & gh & $\mathrm{c}$ & M & 3 & $+{ }^{(1)}$ & & $+(2)$ & Dosba et al, 1992 \\
\hline & & $\mathrm{f}$ & $\mathrm{n}$ & M & 1 & $+(1)$ & & & Audergon et al, 1995b \\
\hline Hasiotico & $?$ & $\mathrm{f}$ & $\mathrm{n}$ & M & 1 & 3.0 & 2.0 & & Audergon et al, 1995b \\
\hline Hatif Colomer & France & $\mathrm{f}$ & $\mathrm{n}$ & M & 4 & 2.2 & 3.0 & & Karayiannis, 1989 \\
\hline Hunter & $?$ & gh & $\mathrm{c}$ & M & 3 & $+(1)$ & & $+(2)$ & Dosba et al, 1992 \\
\hline Hyperproimo & Greece & $\mathrm{f}$ & $\mathrm{n}$ & M & 4 & 2.7 & 3.0 & & Karayiannis, 1989 \\
\hline Imrahor & Iran & $\mathrm{f}$ & $\mathrm{n}$ & M & 4 & 3.0 & 3.0 & & Balan and Stoian, 1995 \\
\hline \multirow[t]{2}{*}{ Irwin } & $?$ & gh & $\mathrm{c}$ & M & 3 & $+(1)$ & & $+(2)$ & Dosba et al, 1988 \\
\hline & & gh & $\mathrm{c}$ & M & 1 & $+(1)$ & & $+(2)$ & Dosba et al, 1991 \\
\hline Jubilena & Yugoslavia & $\mathrm{f}$ & $\mathrm{n}$ & M & 4 & 2.5 & 0.3 & & Karayiannis, 1989 \\
\hline \multirow[t]{2}{*}{ Karakabey } & Yugoslavia & gh & $\mathrm{c}$ & M & 3 & $+(1)$ & & $+(2)$ & Dosba et al, 1992 \\
\hline & & $\mathrm{f}$ & $\mathrm{n}$ & M & 1 & 3.0 & 2.0 & & Audergon et al, 1995b \\
\hline \multirow[t]{2}{*}{ Kishinevska } & Yugoslavia & $\mathrm{f}$ & $\mathrm{n}$ & M & 4 & 2.8 & 1.3 & & Karayiannis, 1989 \\
\hline & & $\mathrm{f}$ & $\mathrm{n}$ & M & 1 & 3.0 & 3.0 & & Audergon et al, $1995 \mathrm{~b}$ \\
\hline Kisineuskij & Yugoslavia & $\mathrm{f}$ & $\mathrm{c}$ & M & 5 & 3.0 & & & Sedlakova and Gallo, 1994 \\
\hline Kostujenska & Yugoslavia & $\mathrm{f}$ & $\mathrm{n}$ & M & 4 & 2.3 & 1.7 & & Karayiannis, 1989 \\
\hline \multirow[t]{2}{*}{ Krymskij } & Yugoslavia & $\mathrm{f}$ & $\mathrm{x}$ & M & 1 & 2.0 & & $+^{(2)(3)}$ & Polák et al, 1995b \\
\hline & & $\mathrm{f}$ & $\mathrm{x}$ & M & 4 & 3.0 & 3.0 & $+(2)$ & Polák et al, 1997 \\
\hline Lambertin & France & gh & $\mathrm{c}$ & M & 3 & $+(1)$ & & $+(2)$ & Dosba et al, 1992 \\
\hline Liberato & Spain & $\mathrm{f}$ & $\mathrm{n}$ & $\mathrm{D}$ & 2 & 0.5 & 2.29 & & Rodríguez et al, 1995 \\
\hline Ligeti & Italy & $\mathrm{f}$ & $\mathrm{c}$ & M & 5 & 3.0 & & & Sedlakova and Gallo, 1997 \\
\hline Litoral & Romania & $\mathrm{f}$ & $\mathrm{n}$ & M & 4 & 2.5 & 2.5 & & Balan and Stoian, 1995 \\
\hline Luizet & France & $\mathrm{f}$ & $\mathrm{n}$ & M & 4 & 2.5 & 1.5 & & Karayiannis, 1989 \\
\hline \multirow[t]{2}{*}{ Madarska } & Romania & $\mathrm{f}$ & $\mathrm{c}$ & M & 5 & 3.0 & & & Sedlakova and Gallo, 1994 \\
\hline & & $\mathrm{f}$ & $\mathrm{n}$ & M & 4 & 2.0 & 0.5 & & Karayiannis, 1989 \\
\hline \multirow[t]{2}{*}{ Mai Chua Sin } & China & $\mathrm{f}$ & $\mathrm{x}$ & M & 2 & 2.0 & & $t^{(2)(3)}$ & Polák et al, 1995b \\
\hline & & $\mathrm{f}$ & $\mathrm{x}$ & M & 4 & 2.0 & 2.5 & $+(2)(4)$ & Polák et al, 1997 \\
\hline Mala Hierba & Spain & $\mathrm{f}$ & $\mathrm{n}$ & $\mathrm{D}$ & 2 & 1.76 & & & Rodríguez et al, 1995 \\
\hline Mandula & Romania & $\mathrm{f}$ & $\mathrm{n}$ & M & & 3.0 & & & Tradafirescu and Topor, 1999 \\
\hline \multirow[t]{2}{*}{ Manicot } & France & gh & $\mathrm{c}$ & $\mathrm{D}$ & 1 & $+(1)$ & & $+(2)$ & Audergon et al, $1995 \mathrm{~b}$ \\
\hline & & gh & $\mathrm{c}$ & $\mathrm{D}$ & 1 & $+(1)$ & & $+(5)$ & Dicenta and Audergon, 1995 \\
\hline \multirow[t]{3}{*}{ Marculesti } & Romania & gh & $\mathrm{c}$ & M & 3 & $+(1)$ & & $+(2)$ & Dosba et al, 1992 \\
\hline & & $\mathrm{f}$ & $\mathrm{n}$ & M & 1 & 3.0 & 3.0 & & Audergon et al, 1995b \\
\hline & & $\mathrm{f}$ & $\mathrm{n}$ & M & & 3.0 & & & Tradafirescu and Topor, 1999 \\
\hline Marraneros & Spain & $\mathrm{f}$ & $\mathrm{n}$ & $\mathrm{D}$ & 2 & 0.1 & & & Rodríguez et al, 1995 \\
\hline Maxgold & USA & $\mathrm{f}$ & $\mathrm{n}$ & M & 4 & 3.0 & 2.8 & & Balan and Stoian, 1995 \\
\hline Mektep & Iran & $\mathrm{f}$ & $\mathrm{n}$ & M & 4 & 3.0 & 2.5 & & Balan and Stoian, 1995 \\
\hline \multirow[t]{2}{*}{ Mitger } & Spain & $\mathrm{f}$ & $\mathrm{c}$ & $\mathrm{D}$ & 1 & 3.0 & 1.0 & & Avinent et al, 1993 \\
\hline & & $\mathrm{f}$ & $\mathrm{n}$ & M & 1 & 3.0 & 3.0 & & Audergon et al, 1995b \\
\hline Mocodoi & $?$ & gh & $\mathrm{c}$ & M & 3 & $+(1)$ & & $+(2)$ & Dosba et al, 1992 \\
\hline
\end{tabular}


Table I. (continued).

\begin{tabular}{|c|c|c|c|c|c|c|c|c|c|}
\hline Cultivar & Origin & Eval & Inoc & Isol & Year & Le s & Fr s & $\mathrm{D} \mathrm{t}$ & Reference \\
\hline Modesto & Spain & $\mathrm{gh}$ & $\mathrm{c}$ & M & 3 & $+(1)$ & & $+(2)$ & Dosba et al, 1988 \\
\hline Monaco Bello & Italy & $\mathrm{f}$ & $\mathrm{n}$ & M & 1 & $+(1)$ & & & Audergon et al, 1995b \\
\hline \multirow[t]{2}{*}{ Moniquí } & Spain & $\mathrm{gh}$ & $\mathrm{c}$ & M & 3 & $+(1)$ & & $+(2)$ & Dosba et al, 1988 \\
\hline & & $\mathrm{f}$ & $\mathrm{n}$ & M & 1 & 3.0 & 2.0 & & Audergon et al, 1995b \\
\hline Moniquí Fino & Spain & $\mathrm{f}$ & $\mathrm{n}$ & $\mathrm{D}$ & 1 & 3.0 & 2.0 & & Audergon et al, 1995b \\
\hline \multirow[t]{2}{*}{ Moorpark } & Australia & $\mathrm{f}$ & $\mathrm{n}$ & M & 4 & 1.0 & 2.0 & & Balan and Stoian, 1995 \\
\hline & & $\mathrm{gh}$ & $\mathrm{c}$ & M & 3 & $+(1)$ & & $+(2)$ & Dosba et al., 1992 \\
\hline Morocco & Morocco & $\mathrm{gh}$ & $\mathrm{c}$ & M & 3 & $+(1)$ & & $+(2)$ & Dosba et al, 1992 \\
\hline Nagy Korosi & Hungary & $\mathrm{f}$ & $\mathrm{n}$ & M & 4 & 1.0 & 1.0 & & Balan and Stoian, 1995 \\
\hline \multirow[t]{2}{*}{ Neptum } & Romania & $\mathrm{f}$ & $\mathrm{n}$ & M & 1 & 3.0 & 2.0 & & Audergon et al, 1995b \\
\hline & & $\mathrm{f}$ & $\mathrm{n}$ & M & 4 & 2.0 & 3.0 & & Balan and Stoian, 1995 \\
\hline NJA19 & USA & $\mathrm{f}$ & $\mathrm{n}$ & M & 4 & 3.0 & 1.5 & & Balan and Stoian, 1995 \\
\hline NJA55 & USA & $\mathrm{f}$ & $\mathrm{n}$ & M & 1 & $+(1)$ & & & Audergon et al, 1995b \\
\hline Nonno & Italy & $\mathrm{f}$ & $\mathrm{n}$ & M & 4 & 1.5 & 3.0 & & Karayiannis, 1989 \\
\hline \multirow[t]{3}{*}{ Olimp } & Romania & $\mathrm{gh}$ & $\mathrm{c}$ & M & 3 & $+(1)$ & & $+(2)$ & Dosba et al, 1992 \\
\hline & & $\mathrm{f}$ & $\mathrm{n}$ & M & 1 & 3.0 & 2.0 & & Audergon et al, 1995b \\
\hline & & $\mathrm{f}$ & $\mathrm{n}$ & M & 4 & 1.0 & 3.0 & & Balan and Stoian, 1995 \\
\hline Ouardi & Tunisia & $\mathrm{f}$ & $\mathrm{n}$ & M & 4 & 2.6 & 2.8 & & Karayiannis, 1989 \\
\hline \multirow[t]{2}{*}{ Palabras } & Spain & $\mathrm{f}$ & $\mathrm{c}$ & $\mathrm{D}$ & 1 & 3.0 & 2.0 & & Avinent et al, 1993 \\
\hline & & $\mathrm{f}$ & $\mathrm{n}$ & M & 1 & 3.0 & 2.0 & & Audergon et al, 1995b \\
\hline \multirow[t]{2}{*}{ Palau } & Spain & $\mathrm{f}$ & $\mathrm{c}$ & $\mathrm{D}$ & 1 & 3.0 & 2.0 & & Avinent et al, 1993 \\
\hline & & $\mathrm{f}$ & $\mathrm{n}$ & $\mathrm{D}$ & 2 & 0.8 & 0.4 & & Rodríguez et al, 1995 \\
\hline Palen & $?$ & $\mathrm{f}$ & $\mathrm{n}$ & M & 1 & 3.0 & 2.0 & & Audergon et al, 1995b \\
\hline \multirow{2}{*}{ Palstein } & S. Africa & $\mathrm{gh}$ & $\mathrm{c}$ & M & 3 & $+(1)$ & & $+(2)$ & Dosba et al, 1988 \\
\hline & & $\mathrm{gh}$ & $\mathrm{c}$ & M & 1 & $+(1)$ & & $+(2)$ & Dosba et al, 1991 \\
\hline Palumella & Italy & $\mathrm{f}$ & $\mathrm{n}$ & M & 1 & 3.0 & 3.0 & & Audergon et al, 1995b \\
\hline \multirow{2}{*}{ Patriarca } & Spain & $\mathrm{gh}$ & $\mathrm{c}$ & M & 3 & $+(1)$ & & $+(2)$ & Dosba et al, 1992 \\
\hline & & $\mathrm{f}$ & $\mathrm{n}$ & M & 4 & 3.0 & 3.0 & & Balan and Stoian, 1995 \\
\hline Paviot & Spain & $\mathrm{f}$ & $\mathrm{n}$ & M & 4 & 2.2 & 2.5 & & Karayiannis, 1989 \\
\hline Pepito & Spain & $\mathrm{f}$ & $\mathrm{n}$ & $\mathrm{D}$ & 2 & 1.6 & 1.4 & & Rodríguez et al, 1995 \\
\hline Pepitos Blancos & Spain & $\mathrm{f}$ & $\mathrm{n}$ & $\mathrm{D}$ & 2 & 0.1 & & & Rodríguez et al, 1995 \\
\hline \multirow[t]{3}{*}{ Polonais } & France & $\mathrm{f}$ & $\mathrm{n}$ & M & 4 & 2.3 & 1.8 & & Karayiannis, 1989 \\
\hline & & gh & $\mathrm{c}$ & M & 3 & $+(1)$ & & $+(2)$ & Dosba et al, 1988 \\
\hline & & $\mathrm{gh}$ & $\mathrm{c}$ & M & 1 & $+(1)$ & & $+(2)$ & Dosba et al, 1991 \\
\hline Portici & Italy & $\mathrm{f}$ & $\mathrm{n}$ & M & 1 & 3.0 & 3.0 & & Audergon et al, 1995b \\
\hline \multirow[t]{2}{*}{ Precoce Boulbon } & France & $\mathrm{f}$ & $\mathrm{n}$ & M & 4 & 2.3 & 2.1 & & Karayiannis, 1989 \\
\hline & & $\mathrm{f}$ & $\mathrm{n}$ & M & 4 & 3.0 & 2.2 & & Elibüyük and Erdiller, 1995 \\
\hline \multirow[t]{3}{*}{ Precoce Pugget } & France & $\mathrm{gh}$ & $\mathrm{c}$ & M & 3 & $+(1)$ & & $+(2)$ & Dosba et al, 1988 \\
\hline & & $\mathrm{gh}$ & $\mathrm{c}$ & M & 3 & $+(1)$ & & $+(2)$ & Dosba et al, 1992 \\
\hline & & $\mathrm{f}$ & $\mathrm{n}$ & M & 1 & $+(1)$ & & & Audergon et al, 1995b \\
\hline \multirow[t]{2}{*}{ Precoce Tirynthos } & Greece & $\mathrm{gh}$ & $\mathrm{c}$ & M & 3 & $+(1)$ & & $+(2)$ & Dosba et al, 1988 \\
\hline & & $\mathrm{f}$ & $\mathrm{n}$ & M & 4 & 2.5 & 3.0 & & Karayiannis, 1989 \\
\hline Precoce Toscana & Italy & $\mathrm{gh}$ & $\mathrm{c}$ & M & 1 & $+(1)$ & & $+(2)$ & Dosba et al, 1991 \\
\hline Precoce Tunisie & Tunisia & $\mathrm{f}$ & $\mathrm{n}$ & M & 4 & 2.6 & 3.0 & & Karayiannis, 1989 \\
\hline Prevette & France & $\mathrm{f}$ & $\mathrm{n}$ & M & 4 & 3.0 & 1.0 & & Balan and Stoian, 1995 \\
\hline Rakowsky & Turkey & $\mathrm{f}$ & $\mathrm{n}$ & M & 4 & 3.0 & 2.2 & & Elibüyük and Erdiller, 1995 \\
\hline \multirow[t]{2}{*}{ Real Fino } & Spain & $\mathrm{f}$ & $\mathrm{n}$ & $\mathrm{D}$ & 2 & 0.1 & & & Rodríguez et al, 1995 \\
\hline & & $\mathrm{gh}$ & $\mathrm{c}$ & $\mathrm{D}$ & 2 & 1.3 & & $+(2)$ & Martínez-Gómez and Dicenta, 2000 \\
\hline Reale d'Imola & Italy & $\mathrm{f}$ & $\mathrm{n}$ & M & 2 & 3.0 & & $+(2)$ & Tradafirescu and Topor, 1999 \\
\hline
\end{tabular}


Table I. (continued).

\begin{tabular}{|c|c|c|c|c|c|c|c|c|c|}
\hline Cultivar & Origin & Eval & Inoc & Isol & Year & Le $s$ & Fr s & $\mathrm{D} \mathrm{t}$ & Reference \\
\hline Reales Cortos & Spain & $\mathrm{f}$ & $\mathrm{n}$ & $\mathrm{D}$ & 2 & 1.3 & 1.9 & & Rodríguez et al, 1995 \\
\hline Ricordo Buonamico & Italy & $\mathrm{f}$ & $\mathrm{n}$ & M & 4 & 2.6 & 2.0 & & Karayiannis, 1989 \\
\hline Roches & Spain & $\mathrm{f}$ & $\mathrm{n}$ & $\mathrm{D}$ & 2 & 0.8 & 0.9 & & Rodríguez et al, 1995 \\
\hline \multirow[t]{2}{*}{ Rojo de Carlet } & Spain & $\mathrm{f}$ & $\mathrm{c}$ & $\mathrm{D}$ & 1 & 3.0 & 1.0 & & Avinent et al, 1993 \\
\hline & & $\mathrm{f}$ & $\mathrm{n}$ & M & 1 & 3.0 & 3.0 & & Audergon et al, 1995b \\
\hline Rouge Rivesaltes & France & $\mathrm{f}$ & $\mathrm{n}$ & M & 4 & 2.2 & 3.0 & & Karayiannis, 1989 \\
\hline \multirow[t]{2}{*}{ Rouge Roussillon } & France & gh & $\mathrm{c}$ & M & 3 & $+(1)$ & & $+(2)$ & Dosba et al, 1988 \\
\hline & & gh & $\mathrm{c}$ & M & 1 & $+(1)$ & & $+(2)$ & Dosba et al, 1991 \\
\hline \multirow[t]{2}{*}{ Rouge Sernhac } & France & gh & $\mathrm{c}$ & M & 3 & $+(1)$ & & $+(2)$ & Dosba et al, 1988 \\
\hline & & gh & c & M & 1 & $+(1)$ & & $+(2)$ & Dosba et al, 1991 \\
\hline Rouge Tardif & France & $\mathrm{f}$ & $\mathrm{n}$ & M & 4 & 2.5 & 3.0 & & Karayiannis, 1989 \\
\hline \multirow[t]{2}{*}{ Royal } & France & gh & $\mathrm{c}$ & M & 3 & $+(1)$ & & $+(2)$ & Dosba et al, 1992 \\
\hline & & $\mathrm{f}$ & $\mathrm{n}$ & M & 4 & 2.0 & 3.0 & & Balan and Stoian, 1995 \\
\hline \multirow[t]{2}{*}{ Sam } & Turkey & gh & $\mathrm{c}$ & M & 3 & $+(1)$ & & $+(2)$ & Dosba et al, 1992 \\
\hline & & $\mathrm{f}$ & $\mathrm{n}$ & M & 4 & 3.0 & 2.2 & & Elibüyük and Erdiller, 1995 \\
\hline \multirow[t]{2}{*}{ San Castresse } & Italy & $\mathrm{f}$ & $\mathrm{x}$ & M & 2 & 1.0 & & $+(2)(3)$ & Polák et al, $1995 \mathrm{~b}$ \\
\hline & & $\mathrm{f}$ & $\mathrm{x}$ & M & 4 & 2.0 & 3.0 & $+^{(2)(4)}$ & Polák et al, 1997 \\
\hline San Francesco & Italy & $\mathrm{f}$ & $\mathrm{n}$ & M & 1 & 3.0 & 3.0 & & Audergon et al, 1995b \\
\hline \multirow[t]{3}{*}{ Saturn } & Romania & gh & $\mathrm{c}$ & M & 3 & $+(1)$ & & $+(2)$ & Dosba et al, 1992 \\
\hline & & $\mathrm{f}$ & $\mathrm{n}$ & M & 1 & 3.0 & 2.0 & & Audergon et al, 1995b \\
\hline & & $\mathrm{f}$ & $\mathrm{n}$ & M & 4 & 3.0 & 2.0 & & Balan and Stoian, 1995 \\
\hline \multirow[t]{2}{*}{ Sayeb Beliana } & Tunisia & $\mathrm{f}$ & $\mathrm{n}$ & M & 4 & 2.7 & 3.0 & & Karayiannis, 1989 \\
\hline & & gh & $\mathrm{c}$ & M & 3 & $+(1)$ & & $+(2)$ & Dosba et al, 1992 \\
\hline \multirow[t]{9}{*}{ Screara } & France & gh & $\mathrm{c}$ & $\mathrm{D}$ & 2 & 2.0 & & & Audergon et al., 1994 \\
\hline & & gh & c & $\mathrm{D}$ & 1 & 3.0 & & & Audergon et al, 1995a \\
\hline & & gh & $\mathrm{c}$ & $\mathrm{D}$ & 1 & $+(1)$ & & $+(5)$ & Dicenta and Audergon, 1995 \\
\hline & & gh & c & M & 3 & $+(1)$ & & $+(2)$ & Dosba et al, 1988 \\
\hline & & $\mathrm{f}$ & $\mathrm{n}$ & M & 4 & 2.5 & 2.8 & & Karayiannis, 1989 \\
\hline & & gh & $\mathrm{c}$ & M & 1 & $+(1)$ & & $+(2)$ & Dosba et al, 1991 \\
\hline & & $\mathrm{f}$ & $\mathrm{n}$ & M & 1 & 2.5 & 2.8 & & Audergon et al, 1995a \\
\hline & & $\mathrm{f}$ & $\mathrm{x}$ & M & 1 & 3.0 & 2.0 & & Audergon et al, 1995a \\
\hline & & $\mathrm{f}$ & $\mathrm{n}$ & M & & 3.0 & & & Tradafirescu and Topor, 1999 \\
\hline \multirow[t]{3}{*}{ Selena } & Romania & gh & $\mathrm{c}$ & M & 1 & $+(1)$ & & $+(2)$ & Dosba et al, 1992 \\
\hline & & $\mathrm{f}$ & $\mathrm{n}$ & M & 1 & 3.0 & 2.0 & & Audergon et al, 1995b \\
\hline & & $\mathrm{f}$ & $\mathrm{n}$ & M & 4 & 2.0 & 2.0 & & Balan and Stoian, 1995 \\
\hline Septembriska & Yugoslavia & $\mathrm{f}$ & $\mathrm{n}$ & M & 1 & 3.0 & 1.0 & & Audergon et al, 1995b \\
\hline \multirow[t]{3}{*}{ Sirena } & Romania & gh & $\mathrm{c}$ & M & 1 & $+(1)$ & & $+(2)$ & Dosba et al, 1992 \\
\hline & & $\mathrm{f}$ & $\mathrm{n}$ & M & 1 & 3.0 & 3.0 & & Audergon et al, 1995b \\
\hline & & $\mathrm{f}$ & $\mathrm{n}$ & M & 4 & 3.0 & 1.0 & & Balan and Stoian, 1995 \\
\hline \multirow[t]{2}{*}{ Skaha } & Canada & $\mathrm{f}$ & $\mathrm{n}$ & M & 1 & 3.0 & 3.0 & & Audergon et al, 1995b \\
\hline & & $\mathrm{f}$ & $\mathrm{n}$ & M & 4 & 2.0 & 1.5 & & Balan and Stoian, 1995 \\
\hline \multirow[t]{2}{*}{ Steam Rosie } & Romania & gh & $\mathrm{c}$ & M & 3 & $+(1)$ & & $+(2)$ & Dosba et al, 1992 \\
\hline & & $\mathrm{f}$ & $\mathrm{n}$ & M & 1 & $+{ }^{(1)}$ & & & Audergon et al, 1995b \\
\hline \multirow[t]{2}{*}{ Sulina } & Romania & $\mathrm{f}$ & $\mathrm{n}$ & M & 1 & 3.0 & 3.0 & & Audergon et al, 1995b \\
\hline & & $\mathrm{f}$ & $\mathrm{n}$ & M & 4 & 1.2 & 3.0 & & Balan and Stoian, 1995 \\
\hline \multirow[t]{3}{*}{ Sulmona } & Romania & gh & $\mathrm{c}$ & M & 1 & $+(1)$ & & $+(2)$ & Dosba et al, 1992 \\
\hline & & $\mathrm{f}$ & $\mathrm{n}$ & M & 4 & 3.0 & 3.0 & & Balan and Stoian, 1995 \\
\hline & & $\mathrm{f}$ & $\mathrm{n}$ & M & 1 & 3.0 & 2.0 & & Audergon et al, 1995b \\
\hline Sungold & USA & $\mathrm{f}$ & $\mathrm{n}$ & M & 4 & 1.0 & 3.0 & & Balan and Stoian, 1995 \\
\hline
\end{tabular}


Table I. (continued).

\begin{tabular}{|c|c|c|c|c|c|c|c|c|c|}
\hline Cultivar & Origin & Eval & Inoc & Isol & Year & Le $s$ & Fr s & $\mathrm{D} \mathrm{t}$ & Reference \\
\hline Szegadti Mamut & Hungary & $\mathrm{f}$ & $\mathrm{n}$ & M & 4 & 1.0 & 3.0 & & Balan and Stoian, 1995 \\
\hline \multirow[t]{3}{*}{ Tadeo } & Spain & gh & $\mathrm{c}$ & M & 3 & $+(1)$ & & $+(2)$ & Dosba et al., 1992 \\
\hline & & $\mathrm{f}$ & $\mathrm{c}$ & $\mathrm{D}$ & 1 & 3.0 & 1.0 & & Avinent et al, 1993 \\
\hline & & $\mathrm{f}$ & $\mathrm{n}$ & M & 1 & 3.0 & 2.0 & & Audergon et al, 1995b \\
\hline Talda & $?$ & gh & $\mathrm{c}$ & M & 3 & $+(1)$ & & $+(2)$ & Dosba et al, 1992 \\
\hline Tardif Bordaneil & France & $\mathrm{f}$ & $\mathrm{n}$ & M & 4 & 2.2 & 2.5 & & Karayiannis, 1989 \\
\hline \multirow[t]{2}{*}{ Timpurii Chisinau } & Moldavia & gh & $\mathrm{c}$ & M & 3 & $+(1)$ & & $+(2)$ & Dosba et al, 1992 \\
\hline & & $\mathrm{f}$ & $\mathrm{n}$ & M & 4 & 3.0 & 3.0 & & Balan and Stoian, 1995 \\
\hline Timpurii Bancasa & Romania & $\mathrm{f}$ & $\mathrm{n}$ & M & 4 & 2.3 & 1.0 & & Balan and Stoian, 1995 \\
\hline \multirow[t]{5}{*}{ Tirynthos } & Greece & gh & $\mathrm{c}$ & $\mathrm{D}$ & 2 & 2.0 & & & Audergon et al, 1994 \\
\hline & & gh & $\mathrm{c}$ & $\mathrm{D}$ & 1 & 2.5 & & & Audergon et al, 1995a \\
\hline & & $\mathrm{f}$ & $\mathrm{n}$ & M & 1 & 3.0 & 3.0 & & Audergon et al, 1995b \\
\hline & & $\mathrm{f}$ & $\mathrm{n}$ & M & 2 & 3.0 & 3.0 & & Audergon et al, 1995a \\
\hline & & $\mathrm{f}$ & $\mathrm{x}$ & M & 2 & 3.0 & 3.0 & & Audergon et al, 1995a \\
\hline \multirow[t]{3}{*}{ Tokaloglu } & Turkey & gh & $\mathrm{c}$ & M & 3 & $+(1)$ & & $+(2)$ & Dosba et al, 1992 \\
\hline & & $\mathrm{f}$ & $\mathrm{n}$ & M & 1 & 3.0 & 3.0 & & Audergon et al, 1995b \\
\hline & & $\mathrm{f}$ & $\mathrm{n}$ & M & 4 & 3.0 & 2.2 & & Elibüyük and Erdiller, 1995 \\
\hline Trandafiniu & & $\mathrm{f}$ & $\mathrm{n}$ & M & 1 & $+(1)$ & & & Audergon et al, 1995b \\
\hline Trevatt & $?$ & gh & $\mathrm{c}$ & M & 3 & $+(1)$ & & $+(2)$ & Dosba et al, 1992 \\
\hline Trujillos & Spain & $\mathrm{f}$ & $\mathrm{n}$ & $\mathrm{D}$ & 2 & 0.2 & 1.4 & & Rodríguez et al, 1995 \\
\hline Ugarska & Yugoslavia & $\mathrm{f}$ & $\mathrm{n}$ & M & 1 & 3.0 & 2.0 & & Audergon et al, 1995b \\
\hline Uleanos & Spain & $\mathrm{f}$ & $\mathrm{n}$ & $\mathrm{D}$ & 2 & 0.6 & & & Rodríguez et al, 1995 \\
\hline Umberto & Romania & $\mathrm{f}$ & $\mathrm{n}$ & M & 4 & 1.0 & 1.0 & & Balan and Stoian, 1995 \\
\hline Velázquez & Spain & $\mathrm{f}$ & $\mathrm{n}$ & $\mathrm{D}$ & 2 & 0.4 & 2.5 & & Rodríguez et al, 1995 \\
\hline \multirow[t]{2}{*}{ Velkopaulovicha } & Czech Rep. & $\mathrm{f}$ & $\mathrm{c}$ & M & 5 & 3.0 & & & Sedlakova and Gallo, 1994 \\
\hline & & $\mathrm{f}$ & $\mathrm{x}$ & M & 4 & 3.0 & 2.5 & $+^{(2)(4)}$ & Polák et al, 1997 \\
\hline \multirow[t]{2}{*}{ Venus } & Romania & $\mathrm{f}$ & $\mathrm{n}$ & M & 1 & 3.0 & 1.0 & & Audergon et al, 1995b \\
\hline & & $\mathrm{f}$ & $\mathrm{n}$ & M & 4 & 2.0 & 3.0 & & Balan and Stoian, 1995 \\
\hline Vesna & Czech Rep. & $\mathrm{f}$ & $\mathrm{c}$ & M & 5 & 3.0 & & & Sedlakova and Gallo, 1994 \\
\hline Vespar & Czech Rep. & $\mathrm{f}$ & $\mathrm{c}$ & M & 5 & 3.0 & & & Sedlakova and Gallo, 1994 \\
\hline \multirow[t]{2}{*}{ Vestar } & Czech Rep. & $\mathrm{f}$ & $\mathrm{x}$ & M & 1 & 2.0 & & $t^{(2)(3)}$ & Polák et al, $1995 \mathrm{~b}$ \\
\hline & & $\mathrm{f}$ & $\mathrm{x}$ & M & 4 & 2.0 & 3.0 & $+^{(2)(4)}$ & Polák et al, 1997 \\
\hline Wenatchee & USA & $\mathrm{f}$ & $\mathrm{n}$ & M & 4 & 3.0 & 3.0 & & Balan and Stoian, 1995 \\
\hline Worley's Peach & USA & $\mathrm{f}$ & $\mathrm{n}$ & M & 4 & 2.0 & 3.0 & & Balan and Stoian, 1995 \\
\hline Zhang Gong Juan & China & $\mathrm{f}$ & $\mathrm{x}$ & M & 1 & 2.0 & & $+^{(2)(3)}$ & Polák et al, $1995 b$ \\
\hline
\end{tabular}

(?): unknown origin.

Eval: evaluation conditions ( $\mathrm{f}=$ field, $\mathrm{gh}=$ greenhouse).

Inoc: inoculation method ( $\mathrm{n}=$ natural, $\mathrm{c}=$ chip, $\mathrm{x}=$ grafting onto an infected tree).

Isol: isolate used ( $\mathrm{M}=$ Marcus, $\mathrm{D}=$ Dideron).

Years: years or cycles of study.

Le s: symptoms in leaves $(0-3),{ }^{(1)}$ Scale not specified.

Fr s: symptoms in fruits $(0-3),{ }^{(1)}$ Scale not specified.

$\mathrm{D}$ t: detection technique, ${ }^{(2)}$ ELISA (+ or -$),{ }^{(3)}$ ISEM (+ or -), ${ }^{(4)}$ IC-RT-PCR (+ or -), ${ }^{(5)}$ TP (+ or -). 
Table II. Apricot cultivars described as resistant to plum pox potyvirus.

\begin{tabular}{|c|c|c|c|c|c|c|c|}
\hline Cultivar & Origin & Eval & Inoc & Isol & Year & $\mathrm{Dt}$ & Reference \\
\hline Alfred & USA & $\mathrm{f}$ & $\mathrm{n}$ & M & 1 & & Rankovic et al, 1999 \\
\hline \multirow[t]{3}{*}{ Avilara } & France & $\mathrm{gh}$ & c & $\mathrm{D}$ & 2 & $-^{(1)}$ & Martínez-Gómez and Dicenta, 2000 \\
\hline & & $\mathrm{f}$ & $\mathrm{n}$ & M & 1 & & Audergon et al, $1995 \mathrm{~b}$ \\
\hline & & $\mathrm{f}$ & $\mathrm{n}$ & M & 5 & $-(1)$ & Karayiannis et al., 1999 \\
\hline Brevira & Germany & $\mathrm{gh}$ & c & $\mathrm{D}$ & 2 & $-(1)$ & Fuchs et al, 1998 \\
\hline Cais Olanda & $?$ & $\mathrm{f}$ & $\mathrm{n}$ & M & 2 & & Tradafiresfu and Topor, 1997 \\
\hline Ceccoona & Italy & $\mathrm{f}$ & $\mathrm{n}$ & M & 4 & & Balan and Stoian, 1995 \\
\hline Framingdale & USA & $\mathrm{f}$ & $\mathrm{n}$ & M & 1 & & Rankovic et al, 1999 \\
\hline \multirow[t]{7}{*}{ Harlayne } & Canada & $\mathrm{gh}$ & $\mathrm{c}$ & $\mathrm{D}$ & 2 & $-(1)$ & Fuchs et al, 1998 \\
\hline & & $\mathrm{gh}$ & $\mathrm{c}$ & M & 3 & $-(1)$ & Dosba et al, 1992 \\
\hline & & $\mathrm{f}$ & $\mathrm{x}$ & M & 2 & - (1) $^{(1)}$ & Karayiannis and Mainou, 1994 \\
\hline & & $\mathrm{f}$ & $\mathrm{n}$ & M & 1 & & Audergon et al, $1995 \mathrm{~b}$ \\
\hline & & $\mathrm{f}$ & $\mathrm{x}$ & M & 2 & -(1) (2) & Polák et al, 1995b \\
\hline & & $\mathrm{f}$ & $\mathrm{n}$ & M & 5 & $-(1)$ & Karayiannis et al., 1999 \\
\hline & & $\mathrm{f}$ & $\mathrm{x}$ & M & 4 & -(1) (3) & Polák et al, 1997 \\
\hline Julskit & Czech Rep. & $\mathrm{f}$ & $\mathrm{c}$ & M & 5 & $-(1)$ & Sedlakova and Gallo, 1994 \\
\hline Karola & Czech Rep. & $\mathrm{f}$ & $\mathrm{c}$ & M & 5 & - $^{(1)}$ & Sedlakova and Gallo, 1994 \\
\hline Kinted & USA & $\mathrm{f}$ & $\mathrm{n}$ & M & 4 & - $^{(1)}$ & Balan and Stoian, 1995 \\
\hline \multirow[t]{2}{*}{ Krupna } & Yugoslavia & $\mathrm{gh}$ & $\mathrm{c}$ & M & 3 & $-^{(1)}$ & Dosba et al.,1992 \\
\hline & & $\mathrm{f}$ & $\mathrm{n}$ & M & 1 & & Rankovic et al, 1999 \\
\hline \multirow[t]{2}{*}{ Leronda } & Czech Rep. & $\mathrm{f}$ & $\mathrm{x}$ & M & 2 & $-(1)(2)$ & Polák et al, 1995b \\
\hline & & $\mathrm{f}$ & $\mathrm{x}$ & M & 4 & $-{ }^{(1)}+{ }^{(3)}$ & Polák et al, 1997 \\
\hline \multirow[t]{4}{*}{ Lito } & Greece & $\mathrm{f}$ & $\mathrm{x}$ & M & 4 & & Syrgiannidis and Mainou, 1991 \\
\hline & & $\mathrm{f}$ & $\mathrm{x}$ & M & 4 & $-(1)$ & Karayiannis and Mainou, 1994 \\
\hline & & $\mathrm{f}$ & $\mathrm{n}$ & M & 1 & & Audergon et al, $1995 \mathrm{~b}$ \\
\hline & & $\mathrm{f}$ & $\mathrm{n}$ & M & 5 & - $^{(1)}$ & Karayiannis et al., 1999 \\
\hline Manitoba & USA & $\mathrm{f}$ & $\mathrm{n}$ & M & 4 & & Balan and Stoian, 1995 \\
\hline \multirow[t]{4}{*}{ NJA2 } & USA & $\mathrm{gh}$ & $\mathrm{c}$ & $\mathrm{D}$ & 2 & - $^{(1)}$ & Martínez-Gómez and Dicenta, 2000 \\
\hline & & $\mathrm{f}$ & $\mathrm{x}$ & M & 4 & $-(1)$ & Karayiannis and Mainou, 1994 \\
\hline & & $\mathrm{f}$ & $\mathrm{n}$ & M & 1 & & Audergon et al, 1995b \\
\hline & & $\mathrm{f}$ & $\mathrm{n}$ & M & 5 & $-(1)$ & Karayiannis et al.,1999 \\
\hline NJA48 & USA & $\mathrm{f}$ & $\mathrm{n}$ & M & 4 & & Balan and Stoian, 1995 \\
\hline NJA53 & USA & $\mathrm{f}$ & $\mathrm{n}$ & M & 4 & & Balan and Stoian, 1995 \\
\hline NJA54 & USA & $\mathrm{f}$ & $\mathrm{n}$ & M & 4 & & Balan and Stoian, 1995 \\
\hline NJA56 & USA & $\mathrm{f}$ & $\mathrm{n}$ & M & 4 & & Balan and Stoian, 1995 \\
\hline NJA58 & USA & $\mathrm{f}$ & $\mathrm{n}$ & M & 0 & & Tradafiresfu and Topor, 1997 \\
\hline NJA59 & USA & $\mathrm{f}$ & $\mathrm{n}$ & M & 4 & & Balan and Stoian, 1995 \\
\hline Orange Red & USA & $\mathrm{gh}$ & $\mathrm{c}$ & $\mathrm{D}$ & 2 & $-(1)$ & Fuchs et al, 1998 \\
\hline \multirow[t]{6}{*}{ Pandora } & Greece & gh & c & $\mathrm{D}$ & 1 & ${ }^{(1)}$ & Martínez-Gómez and Dicenta, 2000 \\
\hline & & $\mathrm{f}$ & $\mathrm{x}$ & M & 4 & & Syrgiannidis and Mainou, 1991 \\
\hline & & $\mathrm{f}$ & $\mathrm{x}$ & M & 8 & $-^{(1)}$ & Karayiannis and Mainou ,1994 \\
\hline & & $\mathrm{f}$ & $\mathrm{n}$ & M & 1 & & Audergon et al, 1995b \\
\hline & & $\mathrm{f}$ & $\mathrm{n}$ & M & 1 & & Audergon et al, 1995b \\
\hline & & $\mathrm{f}$ & $\mathrm{n}$ & M & 5 & ${ }_{-(1)}^{(1)}$ & Karayiannis et al., 1999 \\
\hline \multirow[t]{2}{*}{ Skoplsjanska } & Czech Rep. & $\mathrm{gh}$ & $\mathrm{c}$ & M & 3 & $-^{(1)}$ & Dosba et al, 1992 \\
\hline & & $\mathrm{f}$ & $\mathrm{n}$ & M & 1 & & Rankovic et al, 1999 \\
\hline
\end{tabular}


Table II. (continued)

\begin{tabular}{|c|c|c|c|c|c|c|c|}
\hline Cultivar & Origin & Eval & Inoc & Isol & Year & $\mathrm{D} \mathrm{t}$ & Reference \\
\hline \multirow[t]{15}{*}{ Stella } & USA & gh & c & $\mathrm{D}$ & 2 & & Audergon et al, 1994 \\
\hline & & gh & $\mathrm{c}$ & $\mathrm{D}$ & 2 & & Audergon et al, 1995a \\
\hline & & gh & $\mathrm{c}$ & $\mathrm{D}$ & 4 & $-(1)$ & Martínez-Gómez and Dicenta, 2000 \\
\hline & & $\mathrm{f}$ & $\mathrm{n}$ & M & 8 & & Syrgiannidis, 1980 \\
\hline & & gh & c & M & 3 & - $^{(1)}$ & Dosba et al, 1988 \\
\hline & & $\mathrm{f}$ & $\mathrm{n}$ & M & 4 & & Karayiannis, 1989 \\
\hline & & gh & c & M & 1 & ${ }_{-(1)}^{(1)}$ & Dosba et al, 1991 \\
\hline & & gh & $\mathrm{c}$ & M & 3 & - $^{(1)}$ & Dosba et al, 1992 \\
\hline & & $\mathrm{f}$ & $\mathrm{x}$ & M & 4 & $-^{(1)}$ & Karayiannis and Mainou, 1994 \\
\hline & & $\mathrm{f}$ & $\mathrm{n}$ & M & 1 & & Audergon et al, 1995b \\
\hline & & $\mathrm{f}$ & $\mathrm{n}$ & M & 5 & & Audergon et al, 1995a \\
\hline & & $\mathrm{f}$ & $\mathrm{n}$ & M & 5 & & Audergon et al, 1995a \\
\hline & & $\mathrm{f}$ & $\mathrm{x}$ & M & 2 & $+(1)-(2)$ & Polák et al, 1995b \\
\hline & & $\mathrm{f}$ & $\mathrm{n}$ & M & 4 & & Balan and Stoian, 1995 \\
\hline & & $\mathrm{f}$ & $\mathrm{n}$ & M & & & Rankovic et al, 1999 \\
\hline Veharda & Czech Rep & $\mathrm{f}$ & $\mathrm{c}$ & M & 5 & $-^{(1)}$ & Sedlakova and Gallo, 1994 \\
\hline Virosia & Germany & gh & $\mathrm{c}$ & $\mathrm{D}$ & 2 & $-^{(1)}$ & Fuchs et al, 1998 \\
\hline
\end{tabular}

(?): unknown origin.

Eval: evaluation conditions ( $\mathrm{f}=$ field, $\mathrm{gh}=$ greenhouse).

Inoc: inoculation method $(\mathrm{n}=$ natural, $\mathrm{c}=$ chip, $\mathrm{x}=$ grafting onto an infected tree $)$.

Isol: isolate used ( $\mathrm{M}=$ Marcus, $\mathrm{D}=$ Dideron $)$.

Years: years or cycles of study.

$\mathrm{D}$ t: detection technique, ${ }^{(1)}$ ELISA (+ or -), ${ }^{(2)}$ ISEM (+ or -), ${ }^{(3)}$ IC-RT-PCR (+ or -).

\subsection{Susceptible cultivars}

The susceptible cultivars (Tab. I) have a wide geographic origin (Europe, Asia, Africa, Australia and America), and all showed a positive reaction when ELISA, ISEM, IC-RT-PCR or TP techniques were applied.

As regards the $\mathrm{M}$ and $\mathrm{D}$ strains, no differences were observed between the cultivars in terms of susceptibility (presence versus absence of symptoms) either on leaves or fruits ('Bebecou', 'Canino', 'Colomer', 'Corbató', 'Currot', 'Ginesta', 'Mitger', 'Palabras', 'Rojo Carlet', 'Screara', 'Tadeo' or 'Tirynthos'). However, in some cases, the M isolate may produce slightly more symptoms with a higher intensity than the D isolate, results which reflect the observations of Quiot et al. [41]. However, the data refer to a wide range of cultivars, which were evaluated in different locations under various environmental conditions and by different authors, a factor which should be taken into account when interpreting slight differences.
Susceptible cultivars presented a high degree of correlation between the intensity of the symptoms in both leaves and fruits. However, in some cultivars, such as the Spanish 'Damasco', 'Trujillos' and 'Velázquez', symptoms were much more intense in fruits than in the leaves [44]. As in the previous case, comparisons were not easy because of the different lengths of the evaluation periods and the different methods used.

\subsection{Resistant cultivars}

In resistant cultivars, symptoms in leaves or fruits have never been reported (Tab. II). Most of these cultivars are from North America, as in the case of 'Alfred', 'Farmingdale', 'Kinted', 'Manitoba', 'Orange Red', 'Stella', 'Harlayne', 'NJA2', 'NJA48', 'NJA53', 'NJA54', 'NJA56', 'NJA58' and 'NJA59'. Furthermore, the european resistant cultivars have as resistant parent an American cultivar, as in the case of 'Avilara' (French), 'Lito' and 'Pandora' (Greek) and 
Table III. Apricot cultivars with uncertain resistance to plum pox potyvirus.

\begin{tabular}{|c|c|c|c|c|c|c|c|c|c|c|}
\hline Cultivar & Origin & Level & Eval & Inoc & Isol & Year & Le s & Fr s & $\mathrm{Dt}$ & Reference \\
\hline \multirow[t]{4}{*}{ Badami } & Iran & $\mathrm{r}$ & gh & $\mathrm{C}$ & M & 3 & 0.0 & & $-(2)$ & Dosba et al, 1988 \\
\hline & & $\mathrm{t}$ & gh & $\mathrm{c}$ & M & 1 & 0.0 & & $+(2)$ & Dosba et al, 1991 \\
\hline & & s & gh & c & M & 3 & $+(1)$ & & $+(2)$ & Dosba et al, 1992 \\
\hline & & s & $\mathrm{f}$ & $\mathrm{n}$ & M & 1 & 3.0 & 1.0 & & Audergon et al, 1995b \\
\hline \multirow[t]{2}{*}{ Blenril } & USA & s & $\mathrm{f}$ & $\mathrm{n}$ & M & 4 & 1.9 & 2.0 & & Karayiannis, 1989 \\
\hline & & $\mathrm{r}$ & $\mathrm{f}$ & $\mathrm{n}$ & M & 1 & 0.0 & 0.0 & & Rankovic et al, 1999 \\
\hline \multirow[t]{2}{*}{ Callatis } & Romania & $\mathrm{r}$ & $\mathrm{f}$ & $\mathrm{n}$ & M & 2 & 0.0 & & & Tradafirescu and Topor, 1999 \\
\hline & & s & $\mathrm{f}$ & $\mathrm{n}$ & M & 4 & 2.0 & 2.8 & & Balan and Stoian, 1995 \\
\hline \multirow[t]{2}{*}{ Chuang Zhi Hong } & China & $\mathrm{r}$ & $\mathrm{f}$ & $\mathrm{x}$ & M & 2 & 1.0 & & $+^{(2)(3)}$ & Polák et al, 1995b \\
\hline & & s & $\mathrm{f}$ & $\mathrm{x}$ & M & 4 & 2.0 & 2.5 & $+(2)$ & Polák et al, 1997 \\
\hline \multirow[t]{2}{*}{ Dacia } & Romania & s & $\mathrm{f}$ & $\mathrm{n}$ & M & 4 & 1.5 & 1.5 & & Balan and Stoian, 1995 \\
\hline & & $\mathrm{r}$ & $\mathrm{f}$ & $\mathrm{x}$ & M & 4 & 2.0 & 2.0 & $+(2) 4)$ & Polák et al, 1997 \\
\hline \multirow[t]{3}{*}{ Excelsior } & Romania & s & gh & c & M & 1 & $+(1)$ & & $+(2)$ & Dosba et al, 1991 \\
\hline & & $\mathrm{r}$ & $\mathrm{f}$ & $\mathrm{n}$ & M & 1 & 0.0 & 0.0 & $+(2)$ & Audergon et al, 1995b \\
\hline & & s & $\mathrm{f}$ & $\mathrm{n}$ & M & 4 & 3.0 & 1.5 & & Balan and Stoian, 1995 \\
\hline \multirow[t]{9}{*}{ Goldrich } & USA & s & gh & $\mathrm{c}$ & $\mathrm{D}$ & 2 & $+(1)$ & & $+(2)$ & Fuchs et al, 1998 \\
\hline & & $\mathrm{r}$ & gh & $\mathrm{c}$ & $\mathrm{D}$ & 4 & 0.0 & & $-(2)$ & Martínez-Gómez and Dicenta, 2000 \\
\hline & & $\mathrm{r}$ & gh & c & M & 3 & 0.0 & & $-(2)$ & Dosba et al, 1992 \\
\hline & & $\mathrm{r}$ & $\mathrm{f}$ & $\mathrm{x}$ & M & 2 & 0.0 & 0.0 & $-(2)$ & Karayiannis and Mainou, 1994 \\
\hline & & $\mathrm{t}$ & $\mathrm{f}$ & $\mathrm{n}$ & M & 1 & 0.0 & & & Audergon et al, 1995b \\
\hline & & $\mathrm{t}$ & $\mathrm{f}$ & $\mathrm{n}$ & M & 1 & $+(1)$ & & & Audergon et al, 1995a \\
\hline & & s & $\mathrm{f}$ & $\mathrm{x}$ & M & 1 & 2.0 & & $+(2)(3)$ & Polák et al, 1995b \\
\hline & & $\mathrm{t}$ & $\mathrm{f}$ & $\mathrm{n}$ & M & 5 & $+(1)$ & & & Karayiannis et al., 1999 \\
\hline & & s & $\mathrm{f}$ & $\mathrm{x}$ & M & 4 & 2.0 & 2.5 & $+(2)(4)$ & Polák et al, 1997 \\
\hline \multirow[t]{13}{*}{ Harcot } & Canada & $\mathrm{r}$ & gh & $\mathrm{c}$ & $\mathrm{D}$ & 2 & 0.0 & 0.0 & & Audergon et al, 1994 \\
\hline & & $\mathrm{r}$ & gh & c & $\mathrm{D}$ & 2 & 0.0 & & & Audergon et al, 1995a \\
\hline & & $\mathrm{r}$ & gh & c & $\mathrm{D}$ & 4 & 0.0 & & $-(2)$ & Martínez-Gómez and Dicenta, 2000 \\
\hline & & $\mathrm{r}$ & gh & c & M & 3 & 0.0 & & $-(2)$ & Dosba et al, 1988 \\
\hline & & s & $\mathrm{f}$ & $\mathrm{n}$ & M & 4 & 1.2 & 1.0 & & Karayiannis, 1989 \\
\hline & & $\mathrm{r}$ & gh & c & M & 1 & 0.0 & & $-(2)$ & Dosba et al, 1991 \\
\hline & & s & gh & c & M & 3 & $+(1)$ & & $+(2)$ & Dosba et al, 1992 \\
\hline & & s & $\mathrm{f}$ & $\mathrm{n}$ & M & 6 & 1.2 & 1.5 & & Audergon et al, 1995a \\
\hline & & s & $\mathrm{f}$ & $\mathrm{x}$ & M & 1 & 2.5 & 2.5 & & Audergon et al, 1995a \\
\hline & & s & $\mathrm{f}$ & $\mathrm{x}$ & M & 1 & 2.0 & & $+(2)(3)$ & Polák et al, 1995b \\
\hline & & $\mathrm{r}$ & $\mathrm{f}$ & $\mathrm{n}$ & M & 1 & 0.0 & & & Tradafirescu and Topor, 1999 \\
\hline & & s & $\mathrm{f}$ & $\mathrm{n}$ & M & 1 & $+(1)$ & & $+(1)$ & Rankovic et al, 1999 \\
\hline & & s & $\mathrm{f}$ & $\mathrm{x}$ & M & 4 & 1.5 & 1.0 & $+(2)(4)$ & Polák et al, 1997 \\
\hline \multirow[t]{2}{*}{ Harval } & Canada & s & $\mathrm{f}$ & $\mathrm{x}$ & M & 2 & 3.0 & & $+(2)(3)$ & Polák et al, 1995b \\
\hline & & $\mathrm{r}$ & $\mathrm{f}$ & $\mathrm{x}$ & M & 4 & 1.0 & 1.0 & $+(2)(4)$ & Polák et al, 1997 \\
\hline \multirow[t]{9}{*}{ Henderson } & USA & $\mathrm{r}$ & gh & $\mathrm{c}$ & $\mathrm{D}$ & 2 & 0.0 & 0.0 & & Audergon et al, 1994 \\
\hline & & $\mathrm{r}$ & gh & $\mathrm{c}$ & $\mathrm{D}$ & 2 & 0.0 & & & Audergon et al, 1995a \\
\hline & & s & gh & $\mathrm{c}$ & M & 3 & $+(1)$ & & $+(2)$ & Dosba et al, 1988 \\
\hline & & $\mathrm{r}$ & gh & c & M & 1 & 0.0 & & $-(2)$ & Dosba et al.,1991 \\
\hline & & $\mathrm{r}$ & gh & c & M & 3 & 0.0 & & $-(2)$ & Dosba et al.,1992 \\
\hline & & $\mathrm{r}$ & $\mathrm{f}$ & $\mathrm{x}$ & M & 2 & 0.0 & 0.0 & $-(2)$ & Karayiannis and Mainou ,1994 \\
\hline & & $\mathrm{r}$ & $\mathrm{f}$ & $\mathrm{n}$ & M & 1 & 0.0 & 0.0 & & Audergon et al, 1995b \\
\hline & & s & $\mathrm{f}$ & $\mathrm{n}$ & M & 4 & 1.0 & 2.5 & & Balan and Stoian, 1995 \\
\hline & & $\mathrm{t}$ & $\mathrm{f}$ & $\mathrm{n}$ & M & 5 & 0.0 & & & Karayiannis et al., 1999 \\
\hline
\end{tabular}


Table III. (continued).

\begin{tabular}{|c|c|c|c|c|c|c|c|c|c|c|}
\hline Cultivar & Origin & Level & Eval & Inoc & Isol & Year & Le s & Fr s & $\mathrm{Dt}$ & Reference \\
\hline \multirow[t]{3}{*}{ Marii de Cenad } & Romania & $\mathrm{r}$ & gh & $\mathrm{c}$ & M & 3 & 0.0 & & $-(2)$ & Dosba et al, 1992 \\
\hline & & s & $\mathrm{f}$ & $\mathrm{x}$ & M & 1 & 2.0 & & $+(2)(3)$ & Polák et al, 1995b \\
\hline & & $\mathrm{r}$ & f & $\mathrm{x}$ & M & 4 & 1.0 & 1.0 & $-{ }^{(2)(4)}$ & Polák et al, 1997 \\
\hline \multirow[t]{3}{*}{ Mamaia } & Romania & $\mathrm{r}$ & $f$ & $\mathrm{n}$ & M & 1 & 0.0 & 0.0 & & Audergon et al, 1995b \\
\hline & & s & f & $\mathrm{n}$ & M & 4 & 3.0 & 1.5 & & Balan and Stoian, 1995 \\
\hline & & s & $\mathrm{f}$ & $\mathrm{n}$ & M & 2 & 3.0 & & & Tradafirescu and Topor, 1999 \\
\hline Pentagonála & $?$ & $\mathrm{t}$ & $\mathrm{f}$ & $\mathrm{x}$ & M & 4 & 2.0 & 2.0 & $+^{(2)}(4)$ & Polák et al, 1997 \\
\hline \multirow[t]{2}{*}{ Riland } & USA & $\mathrm{r}$ & $\mathrm{f}$ & $\mathrm{n}$ & M & 0.0 & 0.0 & & & Rankovic et al, 1999 \\
\hline & & s & f & $\mathrm{n}$ & M & 4 & 3.0 & 3.0 & & Balan and Stoian, 1995 \\
\hline Roxana & $?$ & $\mathrm{t}$ & $\mathrm{f}$ & $\mathrm{n}$ & M & 1 & 0.0 & & & Audergon et al, 1995b \\
\hline \multirow{18}{*}{ Stark Early Orange } & USA & $\mathrm{r}$ & gh & c & $\mathrm{D}$ & 2 & 0.0 & 0.0 & & Audergon et al, 1994 \\
\hline & & $\mathrm{r}$ & gh & $\mathrm{c}$ & $\mathrm{D}$ & 1 & 0.0 & & & Audergon et al, 1995a \\
\hline & & $\mathrm{t}$ & gh & $\mathrm{c}$ & $\mathrm{D}$ & 2 & & & $+(2)$ & Fuchs et al, 1998 \\
\hline & & $\mathrm{r}$ & gh & $\mathrm{c}$ & $\mathrm{D}$ & 2 & 0.0 & & $-{ }^{(2)}$ & Martínez-Gómez and Dicenta, 2000 \\
\hline & & $\mathrm{r}$ & $\mathrm{f}$ & $\mathrm{n}$ & M & 8 & 0.0 & 0.0 & & Syrgiannidis, 1980 \\
\hline & & $\mathrm{r}$ & gh & $\mathrm{c}$ & M & 3 & 0.0 & & $-(2)$ & Dosba et al, 1988 \\
\hline & & $\mathrm{r}$ & $\mathrm{f}$ & $\mathrm{n}$ & M & 4 & 0.0 & 0.0 & & Karayiannis, 1989 \\
\hline & & $\mathrm{r}$ & $\mathrm{gh}$ & $\mathrm{c}$ & M & 1 & 0.0 & & $-(2)$ & Dosba et al, 1991 \\
\hline & & $\mathrm{r}$ & $\mathrm{gh}$ & $\mathrm{c}$ & M & 3 & 0.0 & & $-(2)$ & Dosba et al, 1992 \\
\hline & & $\mathrm{r}$ & $\mathrm{f}$ & $\mathrm{x}$ & M & 5 & 0.0 & 0.0 & $-{ }^{(2)}$ & Karayiannis and Mainou, 1994 \\
\hline & & $\mathrm{r}$ & $\mathrm{f}$ & $\mathrm{n}$ & M & 1 & 0.0 & 0.0 & & Audergon et al, $1995 \mathrm{~b}$ \\
\hline & & $\mathrm{r}$ & $\mathrm{f}$ & $\mathrm{n}$ & M & 5 & 0.0 & 0.0 & & Audergon et al, 1995a \\
\hline & & $\mathrm{r}$ & $f$ & $\mathrm{x}$ & M & 5 & 0.0 & 0.0 & & Audergon et al, 1995a \\
\hline & & $\mathrm{r}$ & f & $\mathrm{x}$ & M & 2 & 0.5 & & $t^{(2)(3)}$ & Polák et al, 1995b \\
\hline & & s & $\mathrm{f}$ & $\mathrm{n}$ & M & 4 & 3.0 & 3.0 & & Balan and Stoian, 1995 \\
\hline & & $\mathrm{r}$ & $\mathrm{f}$ & $\mathrm{n}$ & M & 2 & 0.0 & & & Tradafirescu and Topor, 1999 \\
\hline & & $\mathrm{r}$ & $\mathrm{f}$ & $\mathrm{x}$ & M & 4 & 1.0 & 0.0 & $+(2)(4)$ & Polák et al, 1997 \\
\hline & & $\mathrm{r}$ & $\mathrm{f}$ & $\mathrm{n}$ & M & 5 & 0.0 & 0.0 & $-{ }^{(2)}$ & Karayiannis et al., 1999 \\
\hline \multirow[t]{2}{*}{ Sundrop } & Canada & s & $\mathrm{f}$ & $\mathrm{n}$ & M & 4 & 3.0 & 2.5 & & Balan and Stoian, 1995 \\
\hline & & $\mathrm{r}$ & $\mathrm{f}$ & $\mathrm{x}$ & M & 4 & 1.5 & 1.5 & $+(2)(4)$ & Polák et al, 1997 \\
\hline \multirow[t]{5}{*}{ Sunglo } & USA & $\mathrm{r}$ & gh & $\mathrm{c}$ & M & 3 & 0.0 & & $-(2)$ & Dosba et al, 1992 \\
\hline & & $\mathrm{r}$ & $f$ & $\mathrm{x}$ & M & 4 & 0.0 & 0.0 & $-(2)$ & Karayiannis and Mainou, 1994 \\
\hline & & $\mathrm{r}$ & f & $\mathrm{n}$ & M & 1 & 0.0 & 0.0 & & Audergon et al, 1995b \\
\hline & & s & $\mathrm{f}$ & $\mathrm{n}$ & M & 4 & 1.0 & 1.0 & & Balan and Stoian, 1995 \\
\hline & & $\mathrm{r}$ & $\mathrm{f}$ & $\mathrm{n}$ & M & 5 & 0.0 & 0.0 & $-(2)$ & Karayiannis et al., 1999 \\
\hline \multirow[t]{5}{*}{ Veecot } & Canada & $\mathrm{r}$ & gh & $\mathrm{c}$ & M & 3 & 0.0 & & $-{ }^{(2)}$ & Dosba et al, 1992 \\
\hline & & $\mathrm{r}$ & $\mathrm{f}$ & $\mathrm{x}$ & M & 9 & 0.0 & 0.0 & $-(2)$ & Karayiannis and Mainou,,1994 \\
\hline & & $\mathrm{r}$ & $\mathrm{f}$ & $\mathrm{c}$ & M & 5 & 0.0 & 0.0 & $-(2)$ & Sedlakova and Gallo, 1994 \\
\hline & & $\mathrm{r}$ & $f$ & $\mathrm{n}$ & M & 1 & 0.0 & 0.0 & & Audergon et al, 1995b \\
\hline & & s & $\mathrm{f}$ & $\mathrm{x}$ & M & 1 & 2.0 & $+(1)$ & $t^{(2)(3)}$ & Polák et al, 1995b \\
\hline \multirow[t]{2}{*}{ Vegama } & Czech Rep & $\mathrm{r}$ & f & $\mathrm{c}$ & M & 5 & 0.0 & 0.0 & $-(2)$ & Sedlakova and Gallo, 1994 \\
\hline & & s & $f$ & $\mathrm{x}$ & $\mathrm{M}$ & 4 & 3.0 & 3.0 & $+(2)(4)$ & Polák et al, 1997 \\
\hline
\end{tabular}

(?): unknown origin.

Level: level of resistance $(\mathrm{r}=$ resistant, $\mathrm{s}=$ susceptible, $\mathrm{t}=$ tolerant $)$.

Eval: evaluation conditions ( $\mathrm{f}=$ field, $\mathrm{gh}=$ greenhouse).

Inoc: inoculation method $(\mathrm{n}=$ natural, $\mathrm{c}=$ chip, $\mathrm{x}=$ grafting onto an infected tree).

Isol: isolate used ( $\mathrm{M}=$ Marcus, $\mathrm{D}=$ Dideron).

Years: years or cycles of study.

Le s: symptoms in leaves $(0-3),{ }^{(1)}$ scale not specified.

Fr s: symptoms in fruits $(0-3),{ }^{(1)}$ scale not specified.

D t: detection technique, ${ }^{(2)}$ ELISA (+ or -), ${ }^{(3)}$ ISEM (+ or -), ${ }^{(4)}$ IC-RT-PCR (+ or -). 
'Leronda' and 'Veharda' (Czech). North American cultivars are obviously a clear source of resistance.

In addition, other sources of resistance have been found in 'Brevira' and 'Virosia' (German), 'Julskit', 'Karola' and 'Skopljanska' (Czech), 'Ceccona' (Italian), 'Krupna' (Yugoslav) and 'Cais Olanda' (unknown origin), although no clear information can be given on their origin. Furthermore, more experiments are necessary to evaluate the maintenance of their resistance using different strains and in different conditions of evaluation.

ELISA, ISEM or IC-RT-PCR, which were performed on the resistant cultivars 'Avilara', 'Harlayne', 'Julskit', 'Karola', 'Kinted', 'Krupna', 'Lito', 'NJA2', 'Pandora' and 'Veharda', showed a negative reaction $[19,20,28,29,32,39,40]$. On the other hand, 'Stella' tested ELISA-positive but ISEM was negative [39], and 'Leronda' tested ELISA-negative and IC-PCR-positive [40].

Unfortunately, not all the resistant sources were evaluated against all the different strains. 'Alfred', 'Farmingdale', 'Kinted', 'Manitoba', 'NJA48', 'NJA53', 'NJA54', 'NJA56', 'NJA58', 'NJA59', 'Lito', 'Leronda', 'Veharda', 'Julskit', 'Karola', 'Skopljanska', 'Ceccona', 'Krupna' and 'Cais Olanda', were assayed only against $\mathrm{M}$ type isolates, while 'Brevira', 'Orange Red' and Virosia' were only evaluated with D type isolates. Only, 'Avilara', 'Harlayne', 'NJA2', 'Pandora' and 'Stella', were assayed with both D and M strains. Some authors [20, 24, 40] have classified 'Harlayne' as 'immune'.

\subsection{Cultivars of uncertain classification}

Table III shows the cultivars described using different classifications depending on the author in question. Mostly, they come from North America and are alternatively described as resistant, tolerant or susceptible. Such is the case with 'Bleril', 'Goldrich', 'Henderson', 'Riland', 'Stark Early Orange', or 'Sunglo' (American) and 'Harcot', 'Harval', 'Sundrop' or 'Veecot' (Canadian).

Another group is composed of the cultivars 'Callatis', 'Dacia', 'Excelsior', 'Mamaia' and
'Marii de Cenad' (Romanian), 'Vegama' (Czech), 'Pentagonála' and 'Roxana' (unknown origin), 'Badami' (Iranian) and 'Chuang Zhi Hong' (Chinese). Little information is available on this group, and some cultivars have occasionally been described as resistant or tolerant. Further investigations, using different conditions and isolates are necessary before they can be definitively classified.

Analysis of the data in Table III seems to indicate that some cultivars can be classified as resistant or susceptible. 'Badami' seems to be susceptible to $M$ type (in spite of the one reference describing it as resistant). 'Harcot' is probably resistant to D type and susceptible to $M$ type. The classification of 'Henderson' and 'Goldrich' remains unclear because, although they have been described as susceptible by several authors, these cultivars were found to be resistant after two years of being grafted onto very diseased trees [28].

The contradictory information concerning the level of resistance of these cultivars could be explained by the different isolate types used (Marcus or Dideron), different methodologies (evaluation conditions, inoculation type, number of years studied, etc.) or the authenticity and sanitary state of the material examined.

Other uncontrolled factors, such as the evolution of the inoculum during the long period of evaluation, the variability of the pathogen, and possible interactions in plants infected with other pathogens could also have affected the results obtained by the authors.

For these reasons, any classification of cultivars into susceptible or resistant should be accompanied by details of the methods and isolates used. It would be beneficial if the same evaluation method could be established in all countries so that the results obtained could be better contrasted.

On the other hand, breeders could use as sources of resistance cultivars such as 'Goldrich', 'Harcot', 'Henderson', 'Stark Early Orange', 'Sunglo' or 'Veecot', which although susceptible to some isolates, are resistant to the isolates commonly found in the countries where breeding programmes are being carried out. New European resistant cultivars such as 'Avilara', 'Lito' and 'Pandora', 
(descendants of 'Henderson' or 'Stark Early Orange') have been obtained in this way.

\section{References}

[1] Aboul-Ela A., About-Ata A.E., Mazyad H.M., Plum pox virus situation in Egyptian stone fruit trees, Acta Hortic. 488 (1999) 745-751.

[2] Acuña R., Outbreaks of plum pox virus in Chile, in: Book of Abstracts, Conf. plum pox, Bordeaux, 1993, p. 77.

[3] Atanassoff D., Plum pox. A new virus disease, in: Yearbook, Univ. Sofia, Bulgaria, Fac. Agric. Sylvic. 11 (1932) 46-49.

[4] Audergon J.M., Dosba F., Karayiannis I., Dicenta F., Amélioration de l'abricotier pour la résistance à la sharka, EPPO Bull. 24 (1994) 741-748.

[5] Audergon J.M., Morvan G., Dicenta F., Chastelliere G., Karayiannis I., A method to determine the susceptibility of apricot to plum pox virus, Acta Hortic. 384 (1995) 575-579.

[6] Audergon J.M., García J.E., Karayiannis I., Monastra F., Jorge O., Amélioration variétale qualitative et sanitaire de l'abricotier espèce fruitière non excédentaire pour la diversification culturale des zones méditerranéennes en cultures sèches et irriguées, Rapp. Final Projet Eur. CT 90 0016, 1995.

[7] Avinent L., Hermoso de Mendoza A., Llácer G., García S., Transmisión del virus de la sharka y sensibilidad varietal en albaricoquero. II Congr. Ibér. Cienc. Hortíc., Zaragoza, Spain, 1993, pp. 200-206.

[8] Balan V., Stoian E., Susceptibility of certain apricot-tree to the plum pox virus pathogenic action, Acta Hortic. 384 (1995) 565-569.

[9] Biggs A.R., Plum pox potyvirus in USA, in: http://www.caf.wvu.edu/kearneysville/disease_descriptions/ppvresources.html, 1999.

[10] Candresse T., Macquaire G., Lanneau M., Bousalem B., Wetzel T., Quiot-Douine J., Quiot J.B., Dunez J., Detection of plum pox potyvirus and analysis of its molecular variability using immunocapture-PCR, EPPO Bull. 24 (1994) 585-595.

[11] Crescenzi A., d'Aquino L., Comes S., Nuzzaci M., Piazzola P., Characterisation of sweet cherry isolate of plum pox potyvirus, Plant Dis. 81 (1997) 711-714.

[12] Dallot S., Bousalem M., Boeglin M., Renaud L.Y., Quiot J.B., Almond trees and sharka: Assessment under controlled conditions of the susceptibility of almond to the main types of plum pox potyvirus and survey for natural infections in France, in: Joint EPPO/MPU Conf., Almond Protection, Valencia, Spain, 1996, p. 33.

[13] Dicenta F., Audergon J.M., Localization of plum pox virus (PPV) in tissues of susceptible and resistant apricot cultivars, Phytopathol. Med. 34 (1995) 83-87.

[14] Dicenta F., Audergon J.M., Inheritance of resistance to plum pox potyvirus (PPV) in 'Stella' apricot seedlings, Plant Breed. 117 (1998) 579-581.

[15] Dicenta F., García J.E., Gella R., MartínezGómez P., Resistencia al virus de la sharka. Un carácter a mejorar en los albaricoqueros españoles, ITEA 92 (1996) 131-143.

[16] Dicenta F., Pérez-Campoy P., Martínez-Gómez P., García-Brunton J., Botella M.A., Natural spread of sharka disease in fruit tree orchards in Murcia (Spain), Acta Hortic. 488 (1999) 775-778.

[17] Dicenta F., Martínez-Gómez P., Burgos L., Egea J., Inheritance of resistance to plum pox potyvirus (PPV) in apricot (Prunus armeniaca L.), Plant Breed. 119 (2000) 161-164.

[18] Dosba F., Lansac M., Maison P., Massonie G., Audergon J.M., Tolerance to plum pox Virus in apricot, Acta Hort. 235 (1988) 275-281.

[19] Dosba F., Denise F., Maison P., Massonie G., Audergon J.M., Plum pox virus resistance of apricot, Acta Hortic. 293 (1991) 569-579.

[20] Dosba F., Orliac S., Dutranoy F., Maison P., Massonie G., Audergon J.M., Evaluation of resistance to plum pox virus in apricot trees, Acta Hortic. 309 (1992) 211-219.

[21] Dunez J., Plum pox disease of stone fruits in Egypt. Report of a mission to Egypt, TCP/EGY/6756, 1988.

[22] Egea J., Burgos L., Martínez-Gómez P., Dicenta F., Apricot breeding for sharka resistance at the CEBAS-CSIC, Murcia (Spain), Acta Hortic. 488 (1999) 153-157.

[23] Elibüyük S., Erdiller G., The susceptibility of some apricot and plum varieties to plum pox (sharka) virus, Acta Hortic. 384 (1995) 549-552.

[24] Fuchs E., Grünzig M., Kegler H., Investigation on the plum pox virus resistance in different apricot genotypes, Acta Virol. 42 (1998) 222-225.

[25] Kalashyan A., Bilkey N.D., Verderevs T.D., Rubina E.U., Plum pox virus on sour cherry in Moldavia, EPPO Bull. 24 (1994) 645-649. 
[26] Karayiannis I., Susceptibility of apricots cultivars to plum pox virus in Greece, Acta Hortic. 235 (1989) 271-274.

[27] Karayiannis I., Reaction of apricot cultivars to plum pox virus infection, Acta Hortic. 384 (1995) 571-574.

[28] Karayiannis I., Mainou A., Resistance to plum pox virus in apricots, EPPO Bull. 24 (1994) 761-766.

[29] Karayiannis I., Audergon J.M., Di Terlizzi B., Susceptibility of apricot cultivars to plum pox virus disease, Acta Hortic. 488 (1999) 753-759.

[30] Keck M., Stöger A., Russ K., Investigations on the spread of sharka in view of a systematic virus control, Acta Hortic. 309 (1992) 135-137.

[31] Kegler H., Fuchs E., Grünzig M., Schwarz S., Some results of 50 years of research on the resistance to plum pox virus, Acta Virol. 42 (1998) 200-215.

[32] Martínez-Gómez P., Resistencia del albaricoquero (Prunus armeniaca L.) al virus de la sharka (plum pox potyvirus): análisis de aspectos de interés para su aplicación en mejora, Ph.D. thesis, Univ. Murcia, Spain, 1998.

[33] Martínez-Gómez P., Dicenta F., Evaluation of resistance to sharka in the breeding apricot program in CEBAS-CSIC in Murcia (Spain), Acta Hortic. 488 (1999) 731-737.

[34] Martínez-Gómez P., Dicenta F., Evaluation of resistance of apricot cultivars to a Spanish isolate of plum pox potyvirus (PPV), Plant Breed. 119 (2000) 179-181.

[35] Nemchinov L., Hadidi A., Characterisation of the sour cherry strain of plum pox virus, Phytopathology 86 (1996) 575-580.

[36] Németh M., History and importance of plum pox in stone-fruit production, EPPO Bull. 24 (1994) 525-537.

[37] Polák J., Chod J., Oukropec I., The production of sharka-free propagating material of apricots and peaches in Czech Republic, Acta Hortic. 309 (1992) 139-143.

[38] Polák J., Chod J., Oukropec I., Krska B., Pívalová J., Jansta Z., Virological programme in breeding of apricots for resistance to plum pox virus in the Czech Republic, Acta Hortic. 384 (1995) 581-584.

[39] Polák J., Kominek P., Jokes M., Oukropec I., Krska B., The evaluation of resistance of apricots to plum pox virus by ELISA and ISEM, Acta Hortic. 386 (1995) 285-289.
[40] Polák J., Oukropec I., Kominek P., Krska B., Bittóová M., Detection and evaluation of resistance of apricots and peach to plum pox virus, J. Plant Dis. Protect. 104 (1997) 466-473.

[41] Quiot J.B., Labonne G., Boeglin M., Adamolle C., Renaud L.Y., Candresse T., Behaviour of two isolates of plum pox virus inoculated on peach and apricot trees, First results, Acta Hortic. 386 (1995) 290-294.

[42] Rankovic M., Duli-Markovic I., Paunovic S., Sharka virus in apricot and its diagnosis, Acta Hortic. 488 (1999) 783-786.

[43] Refatti E., Osler R., Loi N., Carraro L., Benetti U., Tomasi A., Vindimian M.E., An attempt in progress to eradicate plum pox, Acta Hortic. 235 (1988) 291-297.

[44] Rodríguez J., Andrés V., Gil L., Martínez J., Hita I., Sensibilidad a Sharka en variedades de albaricoquero de Murcia, in: Frutales de Hueso, Fund. La Caixa, Barcelona, Spain, 1995, pp. 56-64.

[45] Roy A.S., Smith I.M., Plum pox situation in Europe, EPPO Bull. 24 (1994) 515-525.

[46] Sedlakova E., Gallo J., Susceptibility of apricot cultivars to artificial inoculations with plum pox potyvirus and use of ELISA for its evaluation, EPPO Bull. 24 (1994) 771-775.

[47] Syrgiannidis G., Selection of two apricot varieties resistant to sharka virus, Acta Phytopathol. Sci. Hung. 15 (1980) 85-87.

[48] Syrgiannidis G., Mainou A., Two new apricot varieties resistant to sharka (plum pox) disease created by crossing, in: Deuxièmes rencontres sur l'abricotier, Avignon, France, 1991, p. 136.

[49] Syrgiannidis G., Mainou A., Karayiannis I., Recherche pour la sélection et création des variétés d'abricotier à la maladie du virus de la sharka, in: Audergon J.M. (Ed.), Agriculture. L'abricotier, INRA, Monfavet, France, 1988, pp. 63-67.

[50] Thakur P.D., Bhardwaj S.V., Garg I.D., Khosla K., Sharma D.R., Detection of plum pox virus in stone fruits from India, in: Symp. Current Trends in Plant Disease Management, Maharashtra, India, 1992.

[51] Tradafirescu M., Topor E., Investigation on the susceptibility of some apricot to plum pox (Sharka) virus, Acta Hortic. 488 (1999) 787-791.

[52] Wetzel T., Candresse T., Ravelonandro M., Delbos R.P., Mayzad H., Aboul-Ata A.E., Dunez J., Nucleotide sequence of the 3'-terminal region of the RNA of the EL Amar strain of plum pox potyvirus, J. Gen. Virol. 72 (1991) 1741-1746. 